\title{
High-resolution mapping of vehicle emissions in China in 2008
}

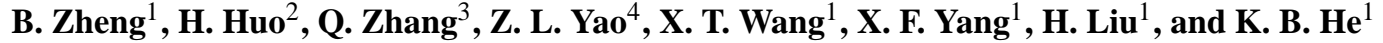 \\ ${ }^{1}$ State Key Joint Laboratory of Environment Simulation and Pollution Control, School of Environment, Tsinghua University, \\ Beijing 100084, China \\ ${ }^{2}$ Institute of Energy, Environment and Economy, Tsinghua University, Beijing 100084, China \\ ${ }^{3}$ Ministry of Education Key Laboratory for Earth System Modeling, Center for Earth System Science, Tsinghua University, \\ Beijing 100084, China \\ ${ }^{4}$ School of Food and Chemical Engineering, Beijing Technology and Business University, Beijing 100048, China
}

Correspondence to: Q. Zhang (qiangzhang@tsinghua.edu.cn) and K. B. He (hekb@tsinghua.edu.cn)

Received: 17 November 2013 - Published in Atmos. Chem. Phys. Discuss.: 9 December 2013

Revised: 24 July 2014 - Accepted: 12 August 2014 - Published: 17 September 2014

\begin{abstract}
This study is the first in a series of papers that aim to develop high-resolution emission databases for different anthropogenic sources in China. Here we focus on on-road transportation. Because of the increasing impact of on-road transportation on regional air quality, developing an accurate and high-resolution vehicle emission inventory is important for both the research community and air quality management. This work proposes a new inventory methodology to improve the spatial and temporal accuracy and resolution of vehicle emissions in China. We calculate, for the first time, the monthly vehicle emissions for 2008 in 2364 counties (an administrative unit one level lower than city) by developing a set of approaches to estimate vehicle stock and monthly emission factors at county-level, and technology distribution at provincial level. We then introduce allocation weights for the vehicle kilometers traveled to assign the county-level emissions onto $0.05^{\circ} \times 0.05^{\circ}$ grids based on the China Digital Road-network Map (CDRM). The new methodology overcomes the common shortcomings of previous inventory methods, including neglecting the geographical differences between key parameters and using surrogates that are weakly related to vehicle activities to allocate vehicle emissions. The new method has great advantages over previous methods in depicting the spatial distribution characteristics of vehicle activities and emissions. This work provides a better understanding of the spatial representation of vehicle emissions in China and can benefit both air quality modeling and management with improved spatial accuracy.
\end{abstract}

\section{Introduction}

Quantifying the magnitude and trend of anthropogenic air pollutants and greenhouse gas (GHG) emissions from China is of great importance because of their negative impact on the environment and their significant contribution to global emission budgets. The community has put tremendous effort into quantifying anthropogenic emissions in China through the development of bottom-up emission inventories (e.g., Streets et al., 2003; Ohara et al., 2007; Zhang et al., 2009). However, the spatial and temporal resolution in existing bottom-up inventories is still very low due to the limitation of emission models and lack of input data (Zhang et al., 2009). This has been recognized as the bottleneck limiting the performance of chemical transport models and the development of emission control strategies. There is an urgent need to develop high spatial and temporal emission profiles with improved accuracy through new emission models and data. This study, the first in a series that will develop high-resolution emission databases for different anthropogenic sources in China, will address emissions from on-road transportation.

On-road transportation contributes significantly to air pollutant emissions in China because of the substantial vehicle growth during the past three decades. It is estimated that vehicles contributed 24,29 and $20 \%$ to national nitrogen oxides $\left(\mathrm{NO}_{\mathrm{x}}\right)$, non-methane volatile organic compound (NMVOC) and carbon monoxide (CO) emissions, respectively, in China in 2006, with higher contributions in urban areas (e.g., 40, 41, and 52\%, respectively, in Beijing) (Zhang et al., 2009). Given the significant impact of vehicles to total 
emissions in China, it is of great importance to estimate vehicle emissions accurately at a high spatial and temporal resolution for both atmospheric chemistry research and air quality management.

Vehicle emissions are difficult to quantify and locate spatially, because they are mobile and affected by many influencing factors, such as vehicle stock, vehicle technology distribution (the shares of different technologies in the fleet), emission factors, and activity levels. Previous studies have developed numerous vehicle emission inventory methods at various resolutions, which can be classified into two broad categories. One method estimates vehicle emissions by road segment on the basis of link-based activity data (Niemeier et al., 2004; Huo et al., 2009; Wang et al., 2009), which has been applied to a few cities in China (Huo et al., 2009; Wang et al., 2009). However, this method is extremely dataintensive and thus difficult to extrapolate to most Chinese cities because of the limited data availability.

The other method estimates emissions at provincial level and allocates total emissions to counties or grids based on surrogates, such as Gross domestic product (GDP) (Cai and Xie, 2007), population density (Wei et al., 2008), or road density (Streets et al., 2003; Ohara et al., 2007; Zhang et al., 2009), by assuming a linear relationship between the surrogates and vehicle emissions of counties or grids within a province. However, these studies often apply national averages for key parameters (such as, technology distributions and vehicle emission factors) to estimate provincial emissions, which can introduce significant errors in the spatial distribution of emissions. Furthermore, many surrogates, such as GDP and population density, are not directly related to vehicle activity. While road density is directly related, it cannot reflect the variation of traffic flow between different roads and, therefore, this allocation method has been considered to have significant uncertainties at city level (Tuia et al., 2007; Ossés de Eicker et al., 2008; Saide et al., 2009). Some studies have improved on this method by using an aggregated surrogate that combines population density, road density and traffic flow (Saide et al., 2009; Zheng et al., 2009). However, this method can only be applied for a few provinces with good data availability because data, such as traffic flow road by road, are not available for the whole of China. Therefore, previous inventory methods are applicable either for a few specific cities, or for provinces and the country but with significant uncertainties resulting from the exclusion of geographical differences in key parameters and the choice of spatial surrogates that are weakly related to vehicle activity. Consequently, existing methods are not able to establish an accurate, high-resolution vehicle emission inventory for China.

There are two important objectives to improve the accuracy and resolution of the vehicle emission inventory of China: (1) to increase the spatial resolution of the key influencing factors of emissions and (2) to develop a gridding method in which the surrogates are strongly related to vehicle activity.

With these two aims in mind, this work developed a new methodology of high-resolution vehicle emission inventory for China. We first developed a county-level vehicle emission inventory that covered 2364 counties in China (county is an administrative unit one level lower than city). To calculate the emissions from vehicles registered in each county, we simulated county-level vehicle stock, province-level technology distribution and county-level emission factors that took into account the geographic differences in local meteorological factors (e.g., temperature and humidity). We then allocated the county-level vehicle emissions onto $0.05^{\circ} \times 0.05^{\circ}$ grids based on the electronic road map of China compiled in 2010, which is the only available data close to 2008. In this step, the total vehicle kilometers traveled (VKT) of each vehicle type in a county was allocated to roads according to the road type. Because the new method differentiated the traffic load on different types of roads, it had advantages over previous allocation methods in depicting the spatial distribution of vehicle activities.

This study focused on $\mathrm{CO}$, non-methane hydrocarbon (NMHC), $\mathrm{NO}_{\mathrm{x}}$ and particulate matters with diameter less than $2.5 \mu \mathrm{m}\left(\mathrm{PM}_{2.5}\right)$ emissions generated from running, starting and evaporative processes of passenger vehicles and trucks in China in 2008. The article is organized as follows: in Sect. 2 we describe the methods to determine the countylevel parameters for calculating county-level vehicle emissions and to allocate the emissions onto grids; in Sect. 3 we analyze the results of key parameters, county-level vehicle emissions and gridded emissions; in Sect. 4 we evaluate the new allocation method by comparing with previous methods and by conducting sensitivity analyses for key assumptions; finally, in Sect. 5 we discuss the main uncertainties of the inventory method and the next step of future work.

\section{Methodology and data}

\subsection{General methodology description}

To develop a high-resolution vehicle emission inventory for China, we estimated vehicle emissions at county-level by exploring the geographic differences in the key parameters as fully as possible, and allocated the county-level emissions onto $0.05^{\circ} \times 0.05^{\circ}$ grids with a new allocation method which could better reflect the spatial distribution characteristics of vehicle activities.

For a given county, emissions from vehicles registered in that county were calculated as follows:

$\mathrm{EMIS}_{k}=\sum_{i} \sum_{j}\left(\mathrm{VP}_{i} \times X_{i, j} \times \mathrm{VKT}_{i} \times \mathrm{EF}_{i, j, k}\right)$,

where $i$ represents vehicle types, including four types of passenger vehicles: heavy-duty buses (HDBs), mediumduty buses (MDBs), light-duty buses (LDBs) and minibuses 
(MBs); and four types of trucks: heavy-duty trucks (HDTs), medium-duty trucks (MDTs), light-duty trucks (LDTs) and mini trucks (MTs); $j$ represents the control technologies (corresponding to pre-Euro I, Euro I, Euro II, Euro III and Euro IV standards); $k$ represents pollutant type (CO, NMHC, $\mathrm{NO}_{\mathrm{x}}$ and $\mathrm{PM}_{2.5}$ in this work); EMIS $k$ is the vehicle emissions of pollutant $k(\mathrm{Mg}) ; \mathrm{VP}_{i}$ is the vehicle population (million); $X_{i, j}$ is the share of vehicles with control technology $j$ in the vehicle type $i$; $\mathrm{VKT}_{i}$ is the average vehicle mileage traveled of vehicle type $i\left(\mathrm{~km}\right.$ year $\left.{ }^{-1}\right)$ and $\mathrm{EF}_{i, j, k}$ is the emission factor of pollutant $k$ of vehicle type $i$ with control technology $j\left(\mathrm{~g} \mathrm{~km}^{-1}\right)$. The research included all counties of the 31 provinces in China, except for Hong Kong, Macau and Taiwan. Motorcycles were excluded from this work because the method of refining spatial resolution of activities from province to county is not applicable to motorcycles given the fact that the growth pattern of motorcycle stock does not follow the GDP-related Gompertz function (Wang et al., 2006).

As Eq. (1) shows, to establish an accurate vehicle emission inventory at county level, it was important to understand the differences in major parameters between counties. By extensive application of available statistical data and existing model tools, we improved the spatial resolution and accuracy of three critical parameters: vehicle population, technology distributions and emission factors.

Different approaches were developed for these parameters: (1) county-level vehicle population was estimated by citylevel Gompertz functions, which were adjusted by countylevel socio-economic status; (2) province-level technology distribution was calculated by provincial vehicle stock and survival functions and (3) monthly county-level emission factors were simulated by the international vehicle emission (IVE) model using China's on-road vehicle emission corrections and county-level meteorological corrections. Sections 2.2-2.4 present the three approaches in detail.

Inter-county traffic also impacts the real-world spatial patterns of vehicle emissions. In this work, we allocated the emissions calculated by Eq. (1) to different road types (highways, national, provincial, and county roads, as defined in Table 1) on the basis of VKT weighting factors considering the effect of inter-county traffic. We then mapped the emissions onto $0.05^{\circ} \times 0.05^{\circ}$ grids according to road densities (for hot-stabilized emissions) and urban populations (for start and evaporation emissions). Details of the emission allocation approach are provided in Sect. 2.5.

\subsection{Modeling vehicle population at county level}

In China, the administrative tiers from high to low are province, city and county, and statistics are not available for county-level vehicle populations. In this work, we developed a model approach to estimate total vehicle population in each county by linking total vehicle ownership (vehicle/1000 people) with its economic development. Vehicle population by
Table 1. Vehicle kilometers traveled allocation weights.

\begin{tabular}{lcccc}
\hline & $\begin{array}{c}\text { Highways }^{\mathrm{a}} \\
\text { Noads }\end{array}$ & $\begin{array}{c}\text { National } \\
\text { roads }^{\mathrm{c}}\end{array}$ & $\begin{array}{c}\text { Provincial }^{\text {rounty }} \\
\text { roads }^{\mathrm{d}}\end{array}$ \\
\hline HDTs & $52 \%$ & $29 \%$ & $11 \%$ & $8 \%$ \\
MDTs & $17 \%$ & $52 \%$ & $18 \%$ & $13 \%$ \\
LDTs and MTs & $21 \%$ & $30 \%$ & $24 \%$ & $25 \%$ \\
HDBs, MDBs, & $20 \%$ on highways, national & $80 \%$ \\
LDBs and MBs & \multicolumn{2}{l}{ roads and provincial roads } \\
\hline
\end{tabular}

a The China Digital Road-network Map (CDRM), which was applied in this study, classified roads into four types: highways, national roads, provincial roads and county roads.

${ }^{b}$ National roads are defined as main roads connecting provincial capitals, economically developed cities and traffic hub cities. The CDRM data separated a proportion of roads from national roads and categorized them as "Highways".

${ }^{\mathrm{c}}$ Provincial roads are defined as main roads connecting cities within a province. The provincial government is responsible for the construction, maintenance and management of provincial roads. The CDRM data separated a proportion of roads from provincial roads, and categorized them as "Highways".

${ }^{d}$ County roads are defined as roads used mainly for transportation within a city. The municipal government is responsible for the construction, maintenance and management of these roads.

type was then split from total vehicle population using the share of vehicle type at provincial level.

The vehicle growth of a region is highly correlated to its economic development (e.g., per-capita GDP), and the Gompertz function (an S-shaped curve with three phases of slow, fast and, finally, saturated growth) is often used to establish the relationship between per-capita GDP and total vehicle ownership (Dargay and Gately, 1999; Dargay et al., 2007; Huo and Wang, 2012). In this study, we used the Gompertz function to hindcast total vehicle ownership at county level using historical GDP data:

Gompertz Function : $V=V^{*} \times e^{\alpha e^{\beta E}}$,

where $V$ represents total vehicle ownership (vehicles/1000 people); $V^{*}$ represents the saturation level of total vehicle ownership (vehicles/1000 people); $E$ represents an economic factor (here, per-capita GDP); and $\alpha$ and $\beta$ are two negative parameters that determine the shape of the curve.

According to Eq. (2), three key parameters must be determined to estimate the total vehicle population of a county: (1) the saturation level $\left(V^{*}\right)$, assumed to be 500 vehicles per 1000 people for all counties in this study, which is a moderate vehicle growth scenario for China (Wang et al., 2006); (2) per-capita GDP $(E)$ of the county, which is obtained from China Statistical Yearbook for Regional Economy (National Bureau of Statistics, 2002-2011) and (3) parameters $\alpha$ and $\beta$ of the county, which are determined by the $\alpha$ and $\beta$ values of the city that this county belongs to and a county-specific adjustment factor, as described below.

$\alpha$ and $\beta$ values can be derived from historical GDP data and vehicle ownership according to the Gompertz function. We first use Eq. (3) (converted from Eq. 2) to derive $\alpha$ and $\beta$ for each city where both GDP and vehicle ownership data 
are available.

$\ln \left(-\ln \left(\frac{V_{i}}{V^{*}}\right)\right)=\ln \left(-\alpha_{i}\right)+\beta_{i} E_{i}$,

where $i$ represents the city that the county belongs to. Citylevel per-capita GDP $\left(E_{i}\right)$ and vehicle ownership data $\left(V_{i}\right)$ were available from 2001 to 2010 from China Statistical Yearbook for Regional Economy (National Bureau of Statistics, 2002-2011).

As shown by Eq. (3), $\ln (-\alpha)$ and $\beta$ were linearly related, and could be regressed from the 10 pairs (data from 2001 to 2010) of known $\ln \left(-\ln \left(V_{i} / V^{*}\right)\right)$ and $E_{i}$. According to the regression results, the mean value of $R$ square $\left(R^{2}\right)$ of the linear regression for all the cities was 0.92 and the median value was 0.96 , indicating that the Gompertz function was reliable for simulating city-level vehicle growth patterns in China. A few cities (e.g., Qiqihar and Jiamusi) showed a poor $R^{2}(<0.5)$. For these cities, as well as those in Tibet, Qinghai and Xinjiang where the statistics are largely incomplete, we used their provincial $\alpha$ and $\beta$ regression parameters instead. In total provincial regression parameters were used for $14 \%$ of the cities.

$\beta$ represents the growth rate of vehicle ownership driven by GDP per-capita. Cities with more GDP per-capita tend to have lower vehicle growth rates (and smaller $\beta$ value) than those cities with less GDP per-capita. Figure 1 illustrated the inverse relationship between $\beta$ and GDP per-capita. Figure 1a compares the $\beta$ values of Hebei and its three cities. As shown in the figure, the three cities had different $\beta$ values from the provincial one. Of the three cities, the richer city has a lower vehicle growth rate because the Gompertz function is S-shaped and the vehicle growth rate slowed down close to the saturation level. Figure $1 \mathrm{~b}$ further shows that the $\beta$ values of the Hebei province and all its cities had a strong inverse correlation with their per-capita GDP in 2008.

When applying $\beta$ derived from each city to counties, it needs to be adjusted as the GDP per-capita in each county varies from the city they belong to. The adjustment factor $k$ is derived as follows:

$k_{i, j}=\left\{\begin{array}{ll}\frac{E_{i, \min }}{E_{j}} & \left(E_{j} \leq E_{i, \min }\right) \\ 1 & \left(E_{i, \min } \leq E_{j} \leq E_{i, \max }\right) \\ \frac{E_{i, \max }}{E_{j}} & \left(E_{j} \geq E_{i, \max }\right)\end{array}\right.$,

where $i$ represents city; $j$ represents county that belong to the city and $E_{j}$ is the per-capita GDP of county $j$ in 2008. $E_{i, \min }$ and $E_{i, \max }$ are the minimum and maximum per-capita GDP during 2001-2010, respectively, used to regress the city-level Gompertz function. If the per-capita GDP of county is in the linearity range of the city Gompertz function (between $E_{i \text {,min }}$ and $E_{i, \max }$ ), we assume the $\beta$ of the county is the same as the value of its city. If the per-capita GDP of a county was out of the range of $E_{i, \min }$ and $E_{i, \max }$, the adjustment factor was calculated as the ratio of the minimum or maximum per-capita GDP of the Gompertz curve to the county per-capita GDP.

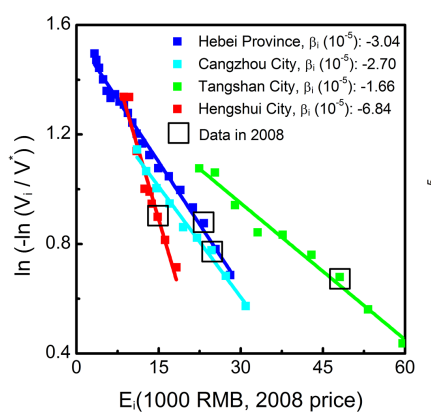

(a)

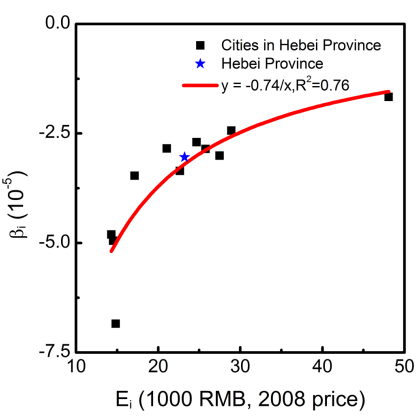

(b)
Figure 1. Gompertz regression of the Hebei Province and its cities: (a) Gompertz function fitting of Hebei versus three selected cities within it (Cangzhou, Tangshan and Hengshui); (b) The relationship between $\beta$ values and per-cap GDP in 2008 of the Hebei province and all its cities.

We assumed the same $\alpha$ for all counties in the same city. The county-level $\alpha$ and $\beta$ could be calculated from Eqs. (5) and (6).

$\alpha_{j}=\alpha_{i}$

$\beta_{j}=k_{i, j} \beta_{i}$

After estimating county-level vehicle ownership using Eq. (2), total vehicle population for each county was calculated by multiplying the total vehicle ownership and population (National Bureau of Statistics, 2009a). The county total vehicle population was further broken down into different vehicle types (HDBs, MDBs, etc.) using the shares of each vehicle type at provincial level (National Bureau of Statistics, 2009 b), implying an assumption that the share of vehicle type is the same for county level and provincial level.

\subsection{Modeling technology distributions}

In this study, the vehicle technology distributions were derived from the age distribution of the fleet and the implementation year of each stage of emission standard, based on the assumption that vehicles registered in a given year comply with the up-to-date emission standards. Because the parameters necessary for the calculation were available only at the provincial level, we simulated province-level vehicle technology distributions and assumed that all counties in one province had the same vehicle technology distribution.

The age distribution of the fleet in 2008 was calculated for each province, as follows:

$A_{i, j}=R_{i} \times S_{i, j-i}$,

where $A_{i, j}$ represents the number of model year $i$ vehicles that survived in target year $j$ ( $j$ is 2008); $R_{i}$ represents the number of newly registered vehicles in year $i$ (model year $i$ vehicles), $i=1994-2008$ and $S_{i, j-i}$ represents the survival rate of model year $i$ vehicles at age $(j-i)$. 
We obtained data for province-level newly registered vehicles $\left(R_{i}\right)$ from 2002 to 2008 from the China Statistical Yearbook (National Bureau of Statistics, 2003-2009). For the period of 1994-2001, where many statistics were missing, we used a back-calculation method to get newly registered vehicle data for each province, as shown in Eq. (8). This method has been applied previously to calculate future projections of the vehicle population of China at the national level (Wang et al., 2006).

$$
\sum_{i=1994}^{j} R_{i} \times S_{i, j-i}=P_{j} \quad(j=1994,1995, \ldots, 2008),
$$

where $i$ represents model year; $j$ represents target year; $R_{i}$ is the number of newly registered vehicles in year $i ; P_{j}$ is the province-level vehicle population in year $j$, which were available from China Statistical Yearbook (National Bureau of Statistics, 1995-2009) and $S_{i, j-i}$ is the survival rates of model year $i$ vehicles at age $(j-i)$, which were calculated separately for passenger vehicles and trucks using the following function:

$S_{i, j-i}=\exp \left[-\left(\frac{(j-i)+b}{T}\right)^{b}\right]$,

where $T$ is associated with vehicle life and $b$ is associated with survival curve decline rate. National average $T$ and $b$ of different vehicle types were first derived based on our previous estimate (Huo and Wang, 2012) as the default for each province. We then use successive approximation approach to adjust $T$ and $b$ for each province to match the registered vehicles numbers calculated by Eq. (9) with the numbers derived from Eq. (8). $T$ and $b$ values of each province are presented in Table $\mathrm{S} 1$ of supplementary information. Note that survival rates were also used in Eq. (7) to calculate the age distribution of the fleet.

\subsection{Modeling emission factors at county level}

Vehicle emissions are influenced by many factors, including technology, fuels, local meteorological conditions and local driving patterns. In the vehicle emission models that are applied worldwide (e.g., the MOBILE model in the United States and the COPERT model in Europe), vehicle emissions are usually estimated using base emission factors measured in a standard environment, and applying correction parameters that can reflect the impact of these influencing factors. In this study, we applied the same method to estimate county-level emission factors in China, by coupling the IVE model developed by the International Sustainable Systems Research Center (Davis et al., 2005), local meteorological correction factors and correction factors based on on-road measurement, as shown in Eq. (10):

$$
\begin{aligned}
\mathrm{EF}_{i, j, k, m} & =\mathrm{EF}_{j, k, m}^{\mathrm{IVE}} \times \eta_{i, j, k} \times \varphi_{j, k} \\
& =\left(\mathrm{BEF}_{j, k, m}^{\mathrm{IVE}} \times K_{j, k}\right) \times \eta_{i, j, k} \times \varphi_{j, k},
\end{aligned}
$$

where $i$ represents the county; $j$ represents the pollutant $\left(\mathrm{CO}, \mathrm{NMHC}, \mathrm{NO}_{\mathrm{x}}\right.$ and $\left.\mathrm{PM}_{2.5}\right) ; k$ represents the vehicle type (e.g., HDBs, MDBs etc.); $m$ represents the IVE vehicle categories, which are categorized by fuels (gasoline and diesel), emission control technologies (e.g., Euro I, and Euro II, etc.) and accumulative mileage $(<80000,80000-160000$, and $>160000 \mathrm{~km}$, because emissions deteriorate as the mileage increases); $\mathrm{EF}_{i, j, k, m}$ is the on-road emission factor of pollutant $j$ of vehicle type $k$ and IVE category $m$ in county $i ; \mathrm{EF}_{j, k, m}^{\mathrm{IVE}}$ is the emission factors simulated by IVE; $\eta_{i, j, k}$ is the local meteorological correction factor, which reflects the effect of local meteorology on vehicle emissions; $\varphi_{j, k}$ is the emission correction factor, which takes into account the difference between the base emission factors embedded in IVE model and the real base emission factors in China and $\mathrm{BEF}_{j, k, m}^{\mathrm{IVE}}$ represents the base emission factors of the vehicle category $k$ measured at an altitude of 500 feet, a temperature of $75^{\circ} \mathrm{F}$, relative humidity of $60 \%$ and under the US Federal Test Procedure (FTP) driving cycle. BEFs are built into the IVE model; $K_{j, k}$ represents driving pattern correction factors, which are simulated in the IVE model using driving bin distributions (Davis et al., 2005).

The main parameters include local driving patterns (to calculate $K$ in IVE), local meteorological correction factors $(\eta)$, and correction factors $(\varphi)$, as shown by Eq. (10).

Local driving patterns were obtained from surveys that we conducted in several Chinese cities, details of the data collection techniques are presented in our previous work (Liu et al., 2007; Yao et al., 2007; Wang et al., 2008). We used the same driving patterns for all counties.

Local meteorological parameters include atmospheric pressure, temperature and humidity, which can significantly affect emission levels (Bishop et al., 2001; Nam et al., 2008; Weilenmann et al., 2009). To use the most recent research findings, we applied the US Environmental Protection Agency's latest model, MOVES (MOtor Vehicle Emission Simulator), to generate monthly county-specific meteorological correction factors $(\eta)$, in which county-level altitude was obtained from the MODIS (moderate resolution imaging spectroradiometer) land use map (Schneider et al., 2009) and county-level monthly mean temperature and humidity from the aggregation of the WRF model v3.3.1 output at $36 \mathrm{~km}$ horizontal resolution.

Correction factors $(\varphi)$ were included because the base emission factors embedded in IVE may not be able to reflect real emission levels in China. The correction factor $\varphi$ is the ratio of measured emission factors to modeled emission factors from the IVE model using the same parameters (driving patterns, meteorological parameters and accumulated mileage) as the measurement conditions. Measured emission factors are collected in 12 Chinese cites using the portable emissions measurement system (PEMS) during the past ten years (Wang et al., 2005; Yao et al., 2007, 2011; Liu et al., 2009; Huo et al., 2012a, b). Correction factor was set as 1 for the vehicle types when local measurements are not 

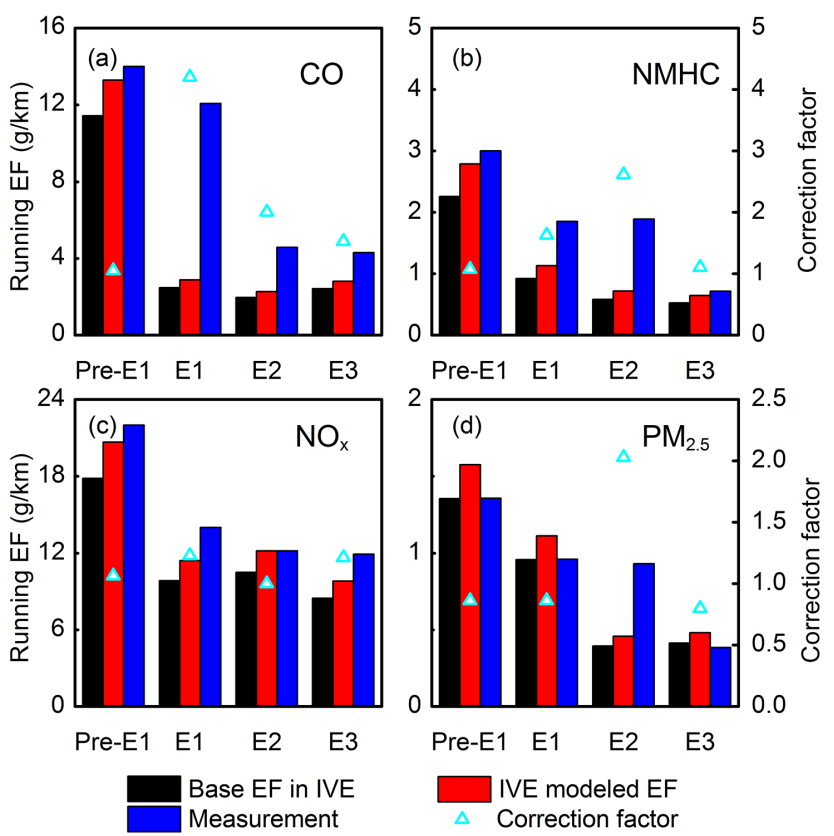

Figure 2. Comparison between measured emission factors for HDTs in China, IVE modeled emission factors and base emission factors in IVE model; and correction factors of HDTs for (a) CO, (b) $\mathrm{NMHC}$, (c) $\mathrm{NO}_{\mathrm{x}}$ and (d) $\mathrm{PM}_{2.5}$.

available. Correction factors remained the same across counties. As an example, Fig. 2 presented the correction factor used for HDTs and compared measured emission factors for HDTs in China (Huo et al., 2012b), IVE modeled emission factors under the same condition, and base emission factors in IVE model. The ratio between measured emission factors and modeled emissions factors represents the differences between base emission factors in IVE and in China, given the fact that the "real" base emission factors for Chinese fleet are unknown.

\subsection{Spatial allocation}

The spatial allocation of vehicle emissions was processed in two steps. First, we used the VKT allocation weights on different types of roads (highway, national, provincial and county roads) to split vehicle activity. Second, we divided the county-level emissions according to road type, then plotted the results onto $0.05^{\circ} \times 0.05^{\circ}$ grids based on road density for hot-stabilized emissions and urban population distributions for start and evaporation emissions.

The truck VKT allocation weights were obtained from a survey conducted in Beijing and Shandong using GPS devices with data acquired over $278 \mathrm{~h}$. The results are presented in Table 1. Heavy duty trucks run more frequently on intercounty (including highways, national and provincial roads) than on county roads, because they are generally used for long-distance transportation. For passenger vehicles, we assumed that they are used more often in urban than in non- urban areas, given that the major purpose of passenger vehicles is to meet people's routine travel needs. Because the VKT survey data of passenger vehicles were absent, we assumed that $80 \%$ of passenger vehicle VKT were driven on county roads and the remaining $20 \%$ on inter-county roads, based on previous estimates (Tuia et al., 2007). To investigate the effect of these VKT weight assumptions on gridded emissions, we performed a sensitivity analysis with different weighting factors (presented in Sect. 4.2).

We assumed that all use of passenger vehicles occurred within the city boundary and the use of trucks within the province boundary. This assumption for trucks may have introduced errors because a proportion of trucks travel between provinces. Unfortunately, the number of trucks used for inter-province transportation is unknown. This issue can be addressed once such traffic flow data become available in China.

Table 2 presented VKT data for different types of vehicles, which is derived from the fuel economy and environmental impact (FEEI) model by assuming that VKT will decline as a vehicle ages and that the VKT of new vehicles varies with the model year (Huo et al., 2012c). VKT remains the same across counties.

Hot-stabilized, start, and evaporative emissions were assigned onto grids by different allocation approaches. Hotstabilized emissions that were split into highway, national, provincial and county roads were allocated onto $0.05^{\circ} \times 0.05^{\circ}$ grids based on road density. We used the China Digital Road-network Map (CDRM) data, a set of new road network data developed in 2010 by National Administration of Surveying, Mapping and Geoinformation of China, instead of the DCW data (Digital Chart of the World), which has been widely applied in previous work (Streets et al., 2003; Ohara et al., 2007; Zhang et al., 2009). The CDRM data is better at representing the road network in urban areas than the DCW data, because it includes more detailed city roads. Start and evaporation emissions were allocated based on the urban population density (ORNL, 2006) given that most vehicle journeys start at parking lots that are close to where people live and work.

\section{Results}

\subsection{County-level vehicle activity}

The spatial distribution of vehicle population represented by county in 2008 is shown in Fig. 3. We observed significant spatial differences in vehicle population and ownership between the counties. Developed cities, such as provincial capitals, industrial and coastal cities, had higher vehicle numbers than less developed cities. For example, counties in the three most economically developed regions - North China Plain (NCP), Yangtze River delta (YRD) and Pearl River delta (PRD) - had 100 to 200 vehicles per 1000 people in 2008, 


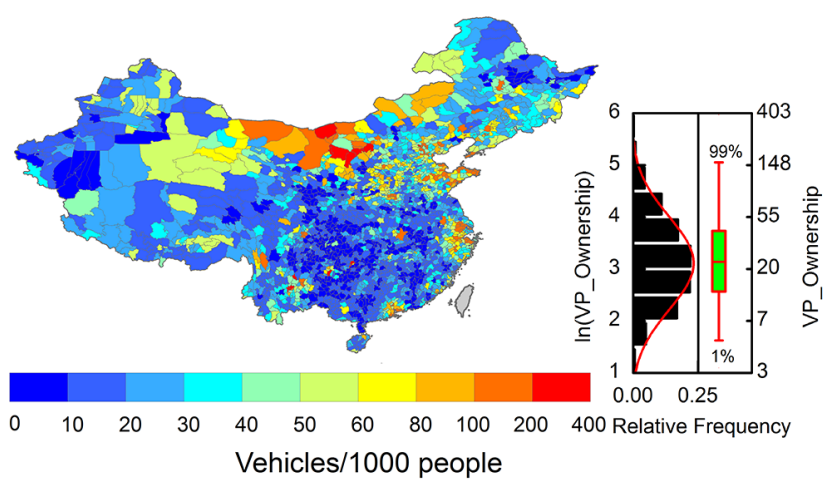

(a)

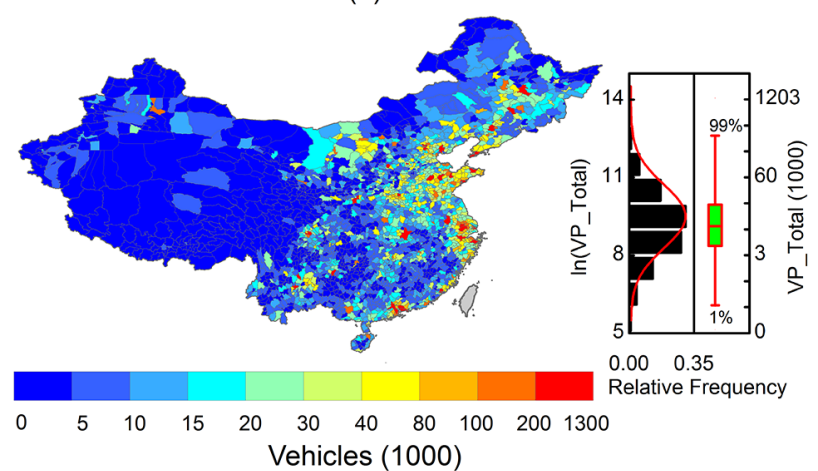

(b)

Figure 3. County-level vehicle population and vehicle ownership in 2008: (a) vehicle ownership (vehicles/1000 people) and (b) vehicle population (1000 units).

whereas the median value in other counties was 23 and $84 \%$ of them had a vehicle ownership level lower than 55 vehicles per 1000 people.

The economic development level affects vehicle ownership significantly. The large difference between counties suggests that they are at different stages of economic growth. Counties in developed regions (e.g., NCP, YRD and PRD) had already entered into the fast growth period, the second growth phase of the Gompertz function, while most other counties had just begun the fast growth phase and thus had a much lower vehicle ownership.

Figure 4 compares the simulated and statistical vehicle population for 665 counties and 311 cities for which statistics were available. As shown in the figure, the simulated vehicle population shows good agreement with the statistical data with an $R^{2}$ greater than 0.9. Note that the method we established to estimate county-level vehicle ownership is less accurate for counties with small vehicle populations, because the number of required vehicles in a country (those used to maintain the basic functioning of society) is not strongly related to economic growth and thus cannot be simulated by the Gompertz function. A large vehicle ownership can reduce the influence of this proportion of vehicles, but for counties with a low vehicle population, the basic need for vehicles accounts
Table 2. National average vehicle kilometers traveled (VKT) in 2008 .

\begin{tabular}{lcccccc}
\hline Category & HDB & MDB & $\begin{array}{c}\text { LDB, } \\
\text { MB }\end{array}$ & HDT & MDT & $\begin{array}{c}\text { LDT, } \\
\text { MT }\end{array}$ \\
\hline $\begin{array}{l}\text { VKT } \\
\left(10^{3} \mathrm{~km}\right)\end{array}$ & 90 & 90 & 15 & 80 & 60 & 30 \\
\hline
\end{tabular}

for a significant share and can therefore reduce the accuracy of the calculation.

\subsection{Technology distributions at provincial level}

Vehicle technology distribution differs significantly between regions, as shown by Fig. 5a. Provinces where emission standards were implemented 1-3 years earlier than the country (e.g., Beijing and Shanghai) tended to have a more technologically advanced fleet. For provinces with the same standard implementation schedule, a larger new vehicle fleet may lead to a smaller share of old vehicles in the future. As shown in Fig. 5b, provinces with higher vehicle growth rates tended to have a lower fraction of pre-Euro 1 vehicles. For example, vehicle numbers grew fastest in Zhejiang, which had $12 \%$ pre-Euro 1 vehicles, and slowest in Xinjiang with $31 \%$ pre-Euro 1 vehicles. Because the emission factors of vehicles compliant with different standards can vary significantly (e.g., $\mathrm{CO}, \mathrm{NMHC}$ and $\mathrm{NO}_{\mathrm{x}}$ emission factors of pre-Euro 1 gasoline LDBs are 15, 40 and 8 times those of their Euro 3 counterparts, respectively) (Huo et al., 2012a), the assumption generally made in previous studies that all provinces (except Beijing and Shanghai) had the same vehicle technology distribution as the national average (Streets et al., 2003; Zhang et al., 2009; Huo et al., 2011) may have involved considerable uncertainties. Therefore, estimating technology distribution at provincial level will improve the accuracy of vehicle emission inventories significantly.

As shown in Fig. 5b, shares of pre-Euro 1 vehicles of the provinces were inversely related to their vehicle growth rates, but Shanghai is an outlier point. With a vehicle growth rate of only $13 \%$, Shanghai had a low share of pre-Euro 1 vehicles equivalent to that of the provinces that have a vehicle growth rate of $23 \%$. The main reason for this is that old vehicles in Shanghai are scrapped at a much faster rate than in other provinces. As Fig. 6 shows, of the 261 counties examined, Shanghai counties had the greatest differences between the number of newly registered vehicles and the net vehicle increase (9\% in Shanghai versus $2 \%$ on average in other counties). The fast vehicle scrapping in Shanghai is attributable to its license plate auction policy, which began in 1994 and limits the number of new license plates available each year, making new license plates expensive. As the percapita GDP grows in Shanghai, people will have the capability to purchase better cars, however, because of the license 


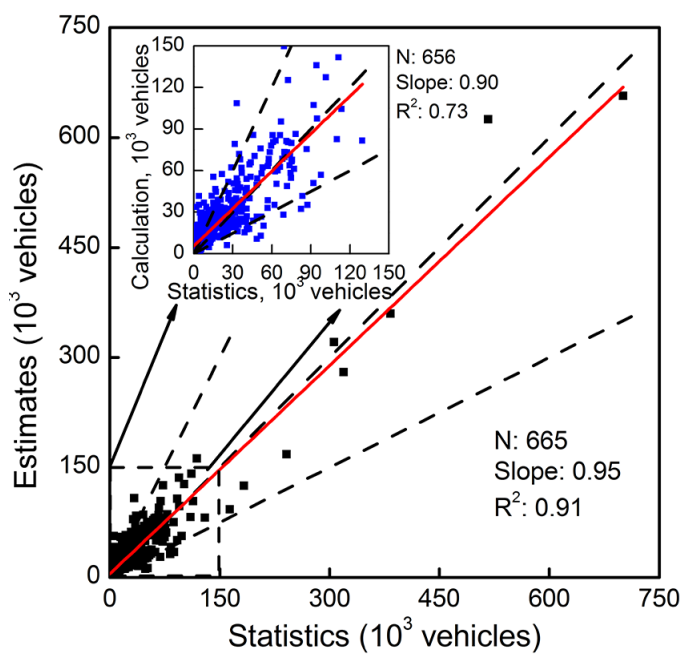

(a)

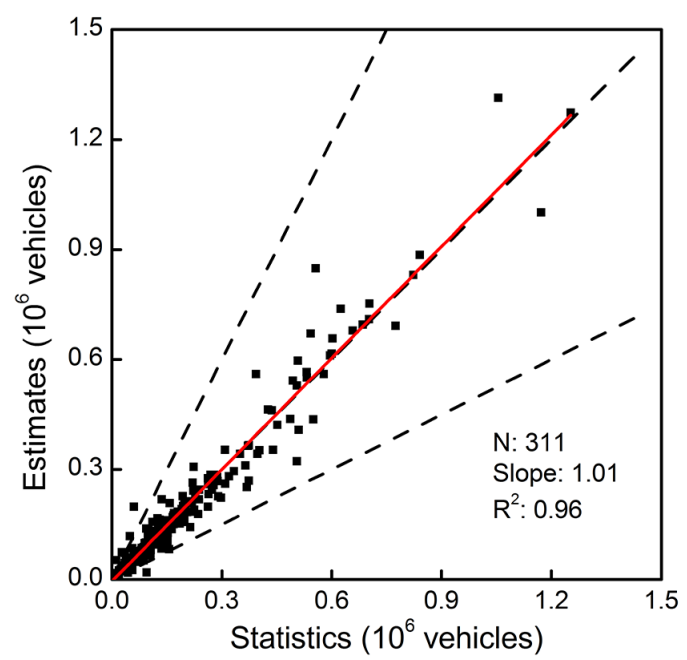

(b)

Figure 4. Comparison of the simulated and statistical vehicle population for (a) 665 counties and (b) 311 cities.

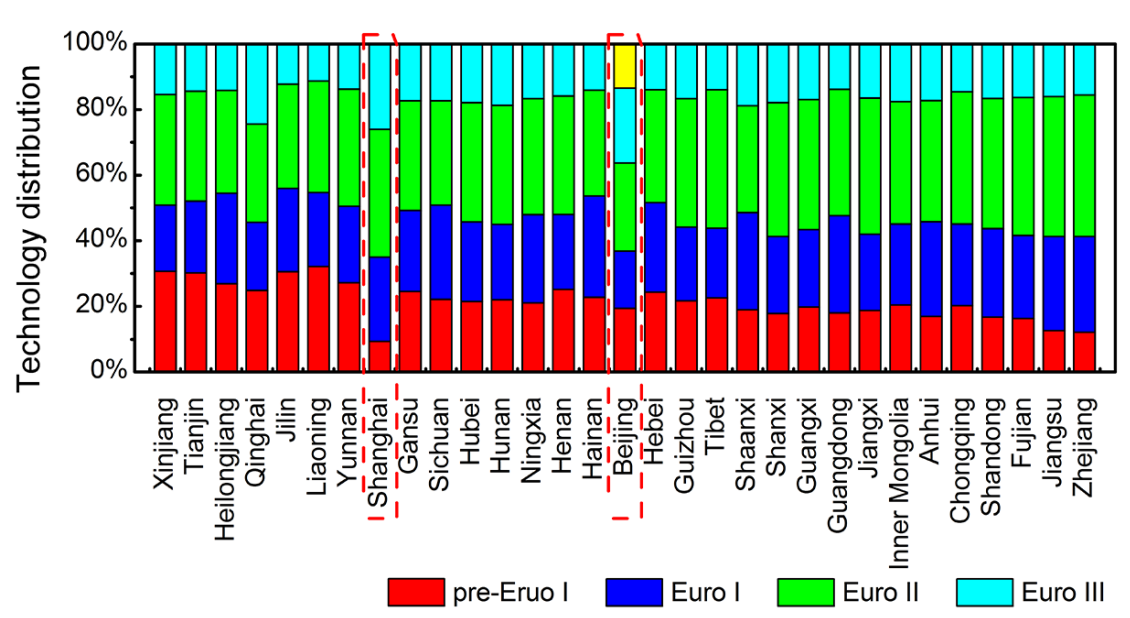

(a)

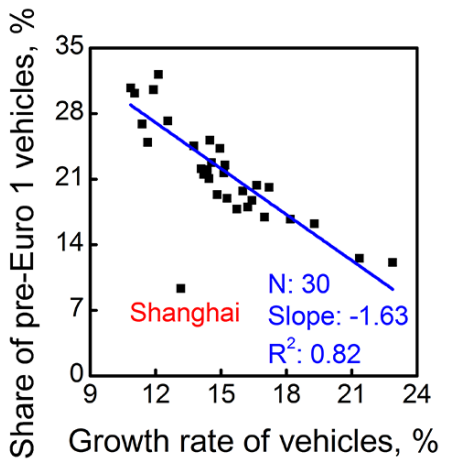

Euro IV

(b)

Figure 5. Relationship between vehicle technology distribution and vehicle growth rates: (a) technology distribution for each province in 2008 (provinces are ranked in order of annual vehicle growth rate from low to high, Beijing and Shanghai are highlighted because they implemented vehicle emission standards ahead of the country); (b) shares of pre-Euro 1 vehicles versus vehicle growth rates of 31 provinces.

The growth rate is defined as the average growth rate between 2002 and 2010.

plate policy, they will have to scrap their old cars before they are able to purchase new ones.

Figure 7 evaluates the back-calculation method by comparing the simulated new vehicle results with statistical records from 2002 to 2010 for 30 provinces ( 270 data points in total, the Hebei Province is not included because of irregularities in the data). As can be seen from Fig. 7, the simulated results showed good agreement with the statistical records, especially for passenger vehicles $\left(R^{2}=0.98\right)$. This indicates that the technology distribution calculated in this study is reliable, and the vehicle survival functions chosen for the provinces can accurately depict the vehicle scrapping patterns.

\subsection{Meteorological correction factors $(\eta)$}

The seasonal meteorological correction factors for NMHC and $\mathrm{CO}$ in light-duty gasoline buses (LDB-G), and for $\mathrm{NO}_{\mathrm{x}}$ in heavy-duty diesel trucks (HDT-D) are shown in Fig. 8. LDB-G and HDT-D were selected as examples because they are the largest contributors to total on-road emissions of $\mathrm{NMHC}, \mathrm{CO}$ and $\mathrm{NO}_{\mathrm{x}}$. In general, $\mathrm{NMHC}$ and $\mathrm{CO}$ running emissions increased as the temperature increased. Conversely, $\mathrm{NO}_{\mathrm{x}}$ running and start emissions increased as the temperature decreased. In addition, start emissions were more sensitive to environmental temperature because, when starting the vehicle, the catalytic converters need 


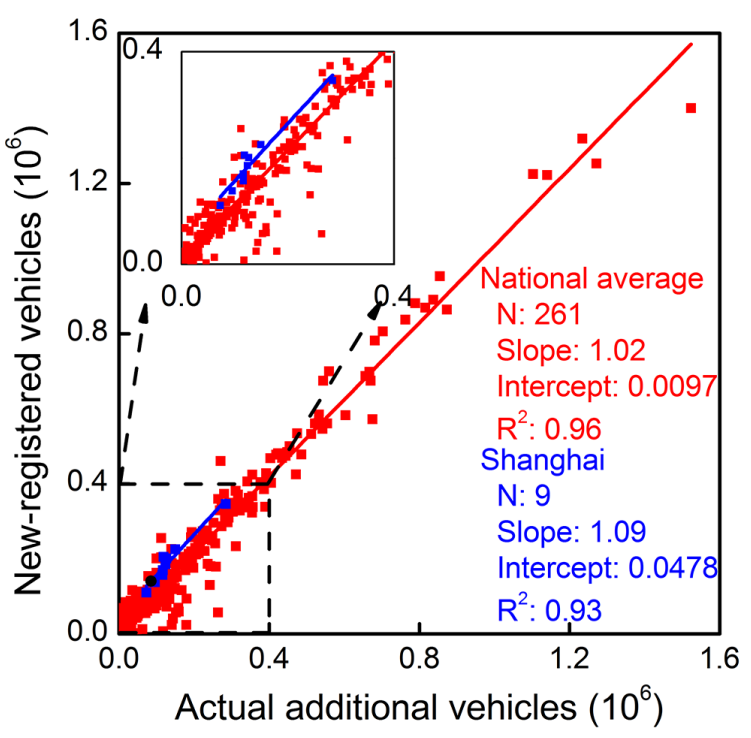

Figure 6. Correlation between newly registered vehicles and vehicle population growth from 2002 to 2010 .

longer/shorter time to reach the working temperature in a colder/warmer climate. For example, from summer (July) to winter (January), the $\mathrm{NO}_{\mathrm{x}}$ start emission factors for HDT-D increased by $5-20$ times while the $\mathrm{NO}_{\mathrm{x}}$ running emissions increased by only 1.1-1.3 times.

The spatial distribution of the correction factors for $\mathrm{CO}$ emissions of LDB-G are presented in Fig. 9. The correction factors varied considerably between northern and southern regions, because the regions differed significantly in temperature. In July, the CO running emission factors in the southern regions were approximately $30 \%$ higher than in the northern regions; while in January, the north had CO start emission factors 3.5 times higher than the south. Figure 9 also reveals the remarkable differences in meteorological correction factors between the western and eastern regions, which were caused not only by their different temperatures but also by their different altitudes. In general, western China is at a higher altitude than eastern China (e.g., $1900 \mathrm{~m}$ in Gansu versus $12 \mathrm{~m}$ in Jiangsu, which are both located at similar latitudes). Higher altitudes can result in more incomplete combustion products (e.g., CO and NMHC) because of the low concentration of oxygen in the atmosphere. Therefore, vehicles operated in the western regions had approximately 9-20\% higher CO emission factors than those in the eastern regions under the same temperature.

The analysis of meteorological correction factors suggests that vehicles with the same control technology may have very different emission factors in different regions. Therefore, the regions with weather conditions that increase vehicle emissions should take stricter control measures. The significant disparity in seasonal and regional correction factors also emphasizes the importance and necessity to calculate emission

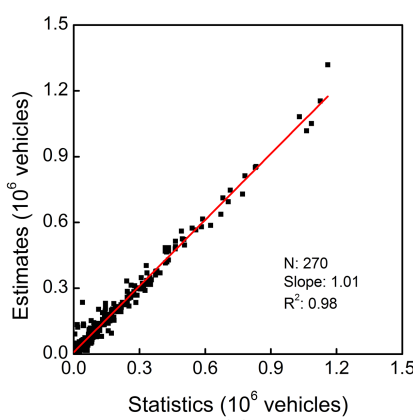

(a)

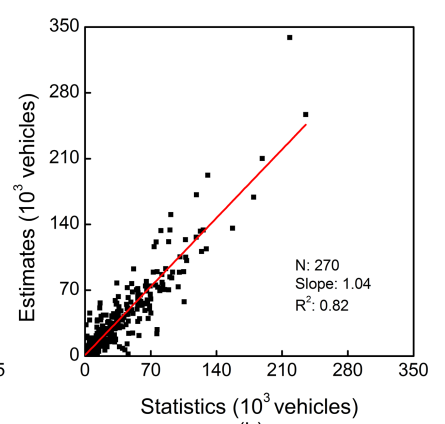

(b)
Figure 7. Comparison of the new vehicles simulated in this work and newly registered vehicles reported in statistics: (a) passenger vehicles and (b) trucks.

factors by region in order to improve the spatial and temporal resolution of the inventory.

\subsection{Total vehicle emissions in 2008}

The on-road CO, NMHC, $\mathrm{NO}_{\mathrm{x}}$ and $\mathrm{PM}_{2.5}$ emissions by vehicle and technology type are summarized in Table 3. In 2008, China's vehicles emitted 16.37 Tg CO, 1.53 Tg NMHC, $4.57 \mathrm{Tg}_{\mathrm{NO}}$ and $0.245 \mathrm{Tg} \mathrm{PM}_{2.5}$. As shown in Table 3, older vehicles (e.g., pre-Euro 1 and Euro 1 vehicles) contributed significantly to on-road emissions. PreEuro 1 vehicles contributed $24-26 \%$ of $\mathrm{CO}$ and NMHC emissions, but only $13-14 \%$ of $\mathrm{NO}_{\mathrm{x}}$ and $\mathrm{PM}_{2.5}$ emissions, and this was because $\mathrm{CO}$ and NMHC emission factors decreased faster than those for $\mathrm{NO}_{\mathrm{x}}$ and $\mathrm{PM}_{2.5}$ from pre-Euro 1 to Euro 1 standards. Euro 3 vehicles contributed more significantly $(17 \%)$ to $\mathrm{NO}_{\mathrm{x}}$ than to other pollutant types, because the reduction in the real-world $\mathrm{NO}_{\mathrm{x}}$ emission factors from Euro 2 to Euro 3 vehicles was very small (Huo et al., 2012b), and new vehicles tended to be used more often than old ones. As demand for long-distance transportation is growing rapidly and heavy duty vehicle numbers are increasing, more stringent control measures should be taken for heavy-duty diesel vehicles in order to control on-road $\mathrm{NO}_{\mathrm{x}}$ emissions.

\subsection{Monthly variation of vehicle emissions}

Monthly vehicle emissions are plotted in Fig. 10. The total emissions, as well as the contributions from different processes (e.g., running the vehicle, starting and evaporation) vary significantly between months. During winter months (Dec to Feb) vehicles produce $19 \%$ more $\mathrm{CO}, 11 \%$ more $\mathrm{NMHC}$, and $21 \%$ more $\mathrm{NO}_{\mathrm{x}}$ emissions than in the summer (Jun to Aug). The monthly $\mathrm{PM}_{2.5}$ emissions did not vary significantly because MOVES assumes that the $\mathrm{PM}_{2.5}$ emission factors of diesel trucks change very little with temperature.

Hot-stabilized processes accounted for the largest proportion of emissions, with $79 \% \mathrm{CO}, 80 \% \mathrm{NMHC}, 97 \% \mathrm{NO}_{\mathrm{x}}$, and $87 \% \mathrm{PM}_{2.5}$ emissions in the summer, and $52 \% \mathrm{CO}$, 

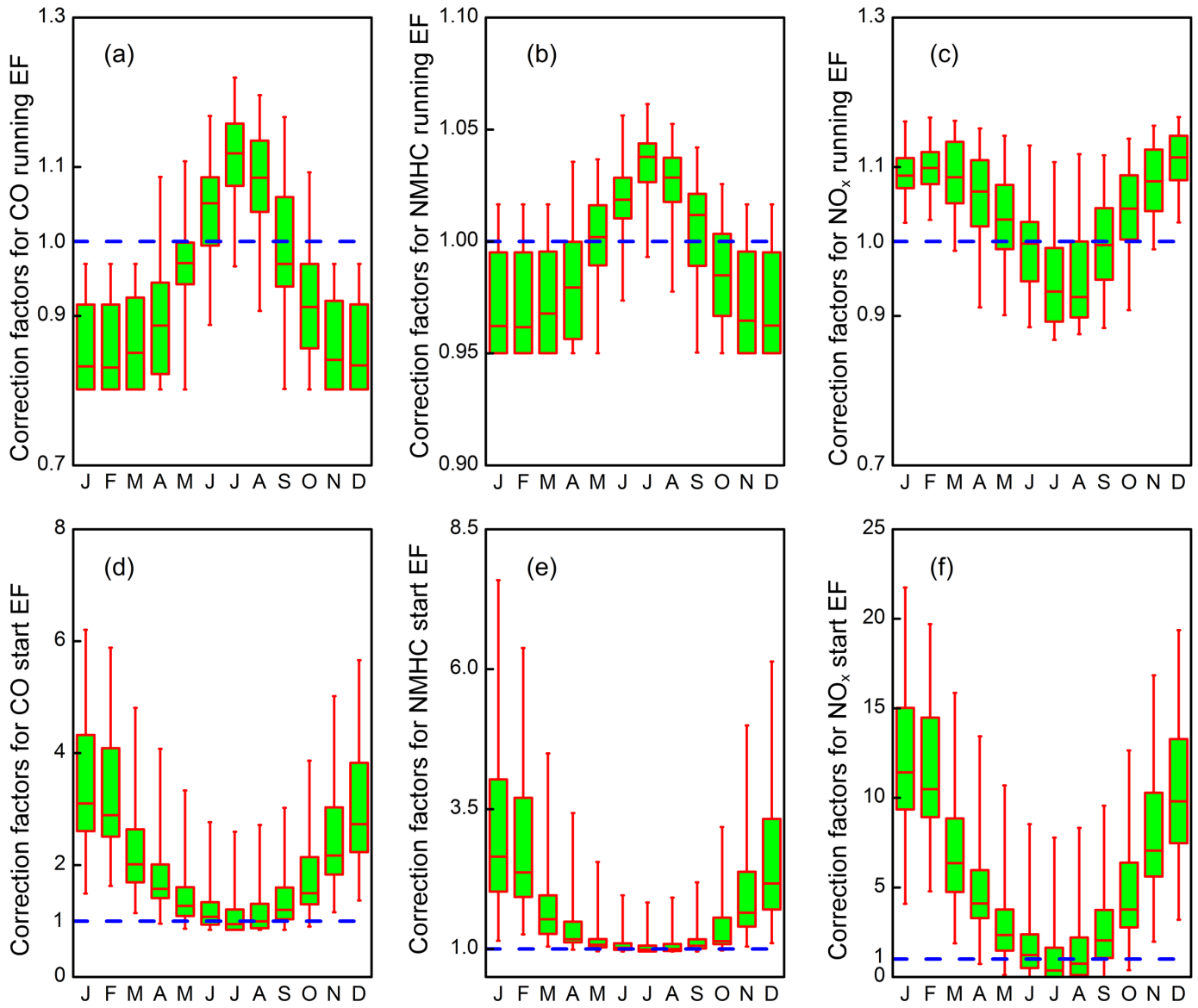

Figure 8. Meteorological correction factors of vehicle emissions by month: (a) running CO of gasoline LDBs; (b) running NMHC of gasoline LDBs; (c) running $\mathrm{NO}_{\mathrm{x}}$ of diesel HDTs; (d) start CO of gasoline LDBs; (e) start NMHC of gasoline LDBs; (f) start NOx of diesel HDTs. Each box plot displays the statistics of 2364 counties in China. The upper line of each box represents the $75 \%$, the middle line the $50 \%$, and the lower line the $25 \%$ quartiles.

$69 \%$ NMHC, $88 \% \mathrm{NO}_{\mathrm{x}}$ and $86 \% \mathrm{PM}_{2.5}$ in winter. The share of $\mathrm{CO}$ and $\mathrm{NMHC}$ start emissions was much higher in winter (48\% for CO and $30 \%$ for NMHC), because when the temperature decreased the $\mathrm{CO}$ and $\mathrm{NMHC}$ start emission factors increased while their running emission factors decreased.

The monthly variability in vehicle emissions at different latitudes is shown in Fig. 11. The monthly pattern of variability of the $\mathrm{CO}$ and NMHC emissions differed remarkably by latitudes due to large contribution from start emissions, which have strong variability at different latitudes induced by differences in temperatures. For $\mathrm{NO}_{\mathrm{x}}$ and $\mathrm{PM}_{2.5}$ emissions, monthly variability was less dependent on latitudes because start emissions play a relatively small role in total $\mathrm{NO}_{\mathrm{x}}$ and $\mathrm{PM}_{2.5}$ emissions, and running emissions are not as sensitive to temperatures as start emissions.

\subsection{Spatial variation of vehicle emissions}

The county and gridded emissions of $\mathrm{CO}$ and $\mathrm{NO}_{\mathrm{x}}$ are depicted in Fig. 12. The NMHC and $\mathrm{PM}_{2.5}$ emission maps are similar to those for $\mathrm{CO}$ and $\mathrm{NO}_{\mathrm{x}}$, respectively, and they are therefore not shown.

Vehicle emissions were distributed unevenly throughout China. The majority of emissions were concentrated in a few counties. Emission hot-spots could be identified, as shown in Fig. 12a. The counties shown in red accounted for less than $1 \%$ of the total counties, but contributed approximately $20 \%$ of the $\mathrm{CO}$ emissions in 2008. Most of these counties are the urban centers of the province capitals, which can be considered as the most developed areas in China.

Urban areas have the highest vehicle emission levels, in terms of both total amount and emission intensity (defined as emissions per unit area). In 2008, urban areas in China accounted for only $11 \%$ of the total land area and $28 \%$ of the total population. However, they contributed 42, 39, 32 and $32 \%$ to the total vehicle $\mathrm{CO}, \mathrm{NMHC} \mathrm{NO}_{\mathrm{x}}$ and $\mathrm{PM}_{2.5}$ emissions, respectively. The share of urban $\mathrm{NO}_{\mathrm{x}}$ and $\mathrm{PM}_{2.5}$ emissions was a little lower because their major contributors, trucks, run less often in urban areas. On average, the urban vehicle emission intensity was 2.9-3.8 times the national 
Table 3. Vehicle emissions in China in 2008.

\begin{tabular}{|c|c|c|c|c|c|c|c|c|c|c|}
\hline & & HDB & MDB & LDB & $\mathrm{MB}$ & HDT & MDT & LDT & MT & Share \\
\hline \multirow{8}{*}{$\begin{array}{l}\mathrm{CO} \\
\text { emissions } \\
(\mathrm{Tg})\end{array}$} & Pre-Euro1 & 0.21 & 0.38 & 1.94 & 0.69 & 0.13 & 0.29 & 0.18 & 0.03 & $24 \%$ \\
\hline & Euro 1 & 0.21 & 0.27 & 2.54 & 0.57 & 0.29 & 0.25 & 0.62 & 0.03 & $29 \%$ \\
\hline & Euro 2 & 0.83 & 0.99 & 3.12 & 0.10 & 0.26 & 0.38 & 0.59 & 0.01 & $38 \%$ \\
\hline & Euro 3 & 0.05 & 0.01 & 1.00 & 0.02 & 0.10 & 0.03 & 0.25 & 0.00 & $9 \%$ \\
\hline & Euro 4 & 0.00 & 0.00 & 0.00 & 0.00 & 0.00 & 0.00 & 0.00 & 0.00 & $0 \%$ \\
\hline & Total & \multirow{3}{*}{\multicolumn{9}{|c|}{$\begin{array}{c}16.37 \\
79 \%, 21 \% \\
88 \%, 12 \%\end{array}$}} \\
\hline & Passenger vehicle/truck & & & & & & & & & \\
\hline & Gasoline/diesel & & & & & & & & & \\
\hline \multirow{8}{*}{$\begin{array}{l}\text { NMHC } \\
\text { emissions } \\
(\mathrm{Tg})\end{array}$} & Pre-Euro1 & 0.02 & 0.03 & 0.19 & 0.07 & 0.03 & 0.03 & 0.03 & 0.00 & $26 \%$ \\
\hline & Euro 1 & 0.02 & 0.02 & 0.21 & 0.04 & 0.04 & 0.03 & 0.08 & 0.00 & $29 \%$ \\
\hline & Euro 2 & 0.11 & 0.09 & 0.14 & 0.00 & 0.11 & 0.06 & 0.09 & 0.00 & $40 \%$ \\
\hline & Euro 3 & 0.01 & 0.00 & 0.01 & 0.00 & 0.02 & 0.01 & 0.03 & 0.00 & $5 \%$ \\
\hline & Euro 4 & 0.00 & 0.00 & 0.00 & 0.00 & 0.00 & 0.00 & 0.00 & 0.00 & $0 \%$ \\
\hline & Total & \multirow{3}{*}{\multicolumn{9}{|c|}{$\begin{array}{c}1.53 \\
64 \%, 36 \% \\
65 \%, 35 \%\end{array}$}} \\
\hline & Passenger vehicle/truck & & & & & & & & & \\
\hline & Gasoline/diesel & & & & & & & & & \\
\hline \multirow{8}{*}{$\begin{array}{l}\mathrm{NO}_{\mathrm{x}} \\
\text { emissions } \\
(\mathrm{Tg})\end{array}$} & Pre-Euro1 & 0.05 & 0.05 & 0.08 & 0.03 & 0.19 & 0.11 & 0.06 & 0.00 & $13 \%$ \\
\hline & Euro 1 & 0.13 & 0.14 & 0.04 & 0.01 & 0.30 & 0.26 & 0.12 & 0.00 & $22 \%$ \\
\hline & Euro 2 & 0.39 & 0.34 & 0.05 & 0.00 & 0.64 & 0.40 & 0.36 & 0.00 & $48 \%$ \\
\hline & Euro 3 & 0.14 & 0.07 & 0.01 & 0.00 & 0.27 & 0.16 & 0.15 & 0.00 & $17 \%$ \\
\hline & Euro 4 & 0.00 & 0.00 & 0.00 & 0.00 & 0.00 & 0.00 & 0.00 & 0.00 & $0 \%$ \\
\hline & Total & \multicolumn{9}{|c|}{4.57} \\
\hline & Passenger vehicle/truck & \multirow{2}{*}{\multicolumn{9}{|c|}{$\begin{array}{c}34 \%, 66 \% \\
9 \%, 91 \%\end{array}$}} \\
\hline & Gasoline/diesel & & & & & & & & & \\
\hline \multirow{8}{*}{$\begin{array}{l}\mathrm{PM}_{2.5} \\
\text { emissions } \\
(\mathrm{Tg})\end{array}$} & Pre-Euro1 & 0.005 & 0.003 & 0.000 & 0.000 & 0.017 & 0.007 & 0.003 & 0.000 & $14 \%$ \\
\hline & Euro 1 & 0.010 & 0.007 & 0.001 & 0.000 & 0.022 & 0.014 & 0.004 & 0.000 & $24 \%$ \\
\hline & Euro 2 & 0.030 & 0.018 & 0.001 & 0.000 & 0.051 & 0.021 & 0.011 & 0.000 & $54 \%$ \\
\hline & Euro 3 & 0.005 & 0.001 & 0.000 & 0.000 & 0.009 & 0.003 & 0.001 & 0.000 & $8 \%$ \\
\hline & Euro 4 & 0.000 & 0.000 & 0.000 & 0.000 & 0.000 & 0.000 & 0.000 & 0.000 & $0 \%$ \\
\hline & Total & \multicolumn{9}{|c|}{0.245} \\
\hline & Passenger vehicle/truck & \multicolumn{9}{|c|}{$33 \%, 67 \%$} \\
\hline & Gasoline/diesel & \multicolumn{9}{|c|}{$3 \%, 97 \%$} \\
\hline
\end{tabular}

average. The differences were even more dramatic in developed areas. Taking Beijing as an example, the six urban districts (including Dongcheng, Xicheng, Haidian, Chaoyang, Fengtai and Shijingshan) accounted for only $8 \%$ of the Beijing surface area, but contributed 53-64\% of the total vehicle emissions for Beijing. The emission intensities of these six districts were 6.3-7.7 times the average of the entire city.

Beijing, Shanghai, Guangzhou and Tianjin had the highest vehicle emissions in China. For example, the vehicle $\mathrm{CO}$ emission intensity was 45, 34, 27 and 17 times higher, respectively, than the average urban emission intensity for the country. Beijing, Shanghai and Guangzhou have implemented restriction policies on car purchases to constrain the excessive vehicle growth, address traffic congestion and reduce vehicle emissions. Similar measures are planned for Tianjin.
Gridded $\mathrm{CO}$ and $\mathrm{NO}_{\mathrm{x}}$ emissions are presented in Fig. $12 \mathrm{~b}$ and $\mathrm{d}$. The majority of vehicle emissions were concentrated in urban areas and on inter-county highways connecting major cities. However, the spatial distribution of $\mathrm{CO}$ and $\mathrm{NO}_{\mathrm{x}}$ emissions had notable differences. CO (NMHC) emissions were highly concentrated in urban areas, while much of the $\mathrm{NO}_{\mathrm{x}}\left(\mathrm{PM}_{2.5}\right)$ emissions were distributed on highways. This difference can be attributed to the fact that light-duty vehicles, the major contributor of $\mathrm{CO}$ and $\mathrm{NMHC}$, are operated more frequently on county roads. On the other hand, heavy duty vehicles (HDBs and HDTs), the major $\mathrm{NO}_{\mathrm{x}}$ and $\mathrm{PM}_{2.5}$ contributors, are used extensively on inter-county roads. 


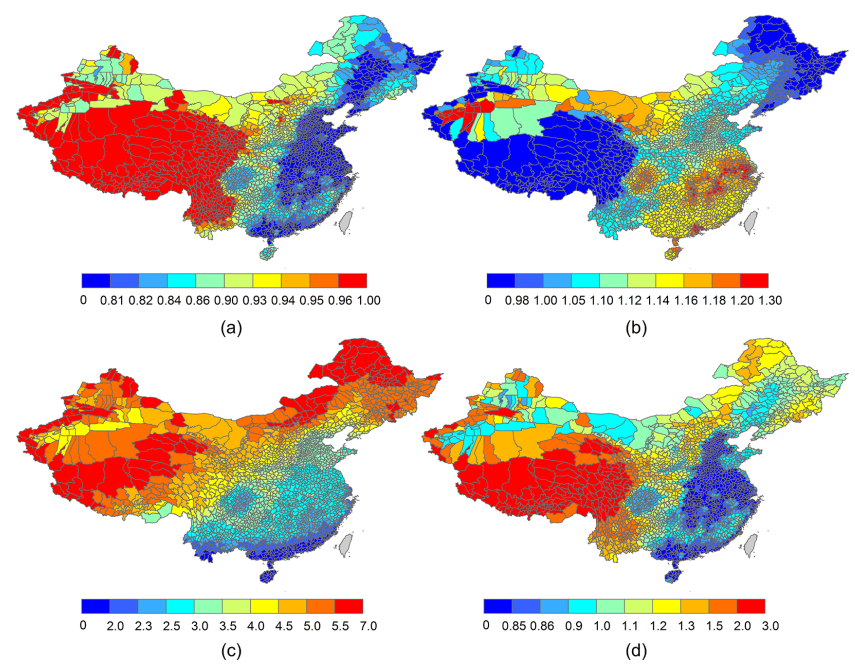

Figure 9. Spatial distribution of the meteorological correction factors for CO emissions of gasoline LDBs by county: (a) running emissions in January; (b) running emissions in July; (c) start emissions in January and (d) start emissions in July.
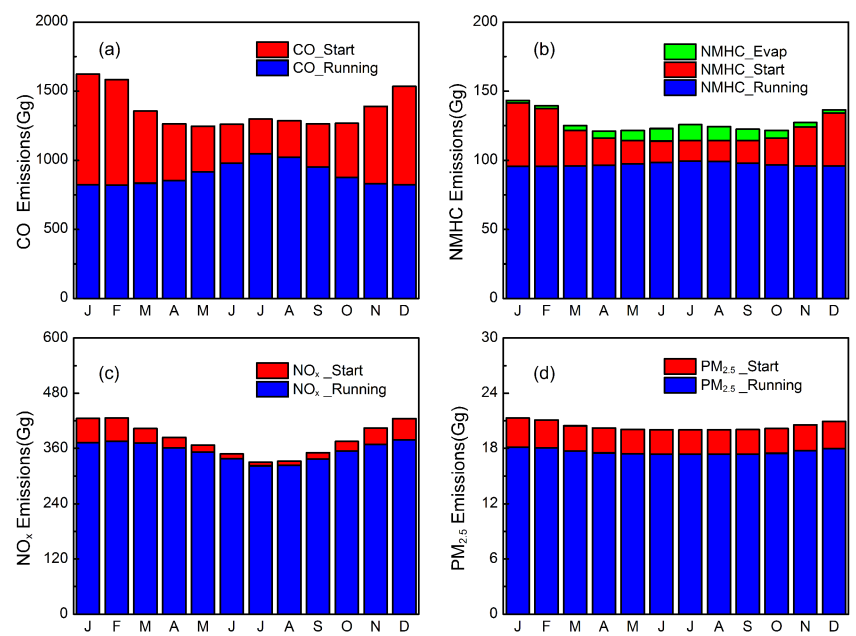

Figure 10. Monthly variations of vehicle emissions in 2008: (a) CO; (b) $\mathrm{NMHC}$; (c) $\mathrm{NO}_{\mathrm{x}}$ and (d) $\mathrm{PM}_{2.5}$.

\section{Evaluation of the spatial allocation method}

\subsection{Spatial surrogates}

Spatial surrogates are important because the extent to which they can represent the spatial distribution of emissions directly determines the accuracy of an emission inventory. The major differences between the spatial proxies used in this study and those applied in previous studies are (1) VKT weight factors for different road types were used to allocate county emissions, which were usually neglected in previous work (Streets et al., 2003; Ohara et al., 2007; Zhang et al., 2009), and (2) the new CDRM data was adopted instead of DCW data.

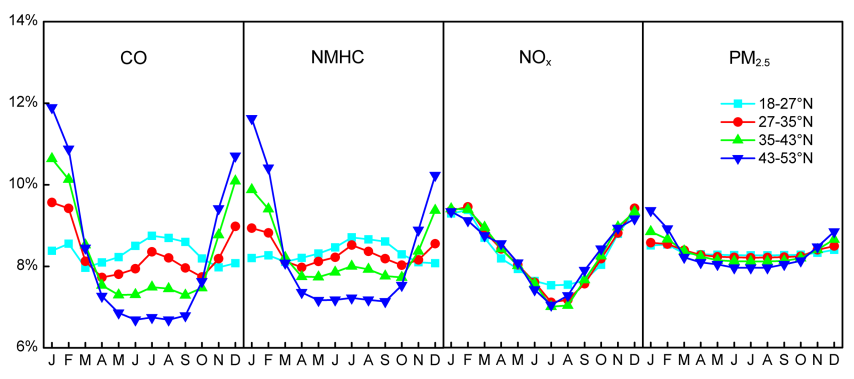

Figure 11. Share of monthly emissions of the whole year at different latitudes. Counties here are located in regions with the altitudes lower than $1000 \mathrm{~m}$ and the longitudes larger than $103^{\circ} \mathrm{E}$.

To evaluate the improvement provided by the new allocation method developed in this study, we compared the new method with three existing allocation methods: (1) the population-based allocation method (M1), (2) the road-length-based allocation method using DCW data (M2) and (3) the road-length-based allocation method using the CDRM data (M3) to explore the effect of road data quality. Details on the four methods are provided in Table 4.

The differences in grid vehicle emissions between our method and the other three methods are illustrated in Fig. 13. Compared with M1, this study generated higher emissions for rich counties with small populations, and lower emissions for less-developed counties with large populations. This is a more reasonable result than that of M1 where the ratio of vehicle activities or emissions was assumed to be proportional to population size. As mentioned in Sect. 2.2, vehicle population is determined by both per-capita GDP and total population. The population-based allocation method (M1) neglects the effect from per-capita GDP on vehicle ownership. More importantly, our work improves the estimates for super-large counties with a population over 2 million. Super-large cities are usually the most industrialized and developed cities in China (e.g., megacities, provincial capitals and coastal cities) and have much higher percentage of vehicle ownership than the national average, and therefore the population-based method could underestimate their emissions. As shown in Fig. 13b and c, the road-length-based methods (M2 and M3) significantly underestimated the emissions for counties with high population or per-capita GDP, and thus failed to identify emission hotspots. When compared with the method developed in this study, the relative differences in M3 were smaller than those in M2 because the new CDRM data has more detailed information on urban roads that can improve spatial allocation in urban areas. However, the underestimation of emissions for urban areas is not addressed completely.

The comparison of gridded emissions at different spatial resolutions is presented in Fig. 14; as shown in the figure, because the population-based method (M1) treats vehicle emissions as area sources, it failed to depict their spatial 
Table 4. Description of the four emission allocation methods.

\begin{tabular}{ll}
\hline Method & Description \\
\hline $\begin{array}{l}\text { Method developed } \\
\text { in this work }\end{array}$ & $\begin{array}{l}\text { Emissions by county are allocated into grids based on the China Digital } \\
\text { Road-network Map (CDRM) and the traffic weights of different road types. }\end{array}$ \\
\hline Method 1 (M1) & Provincial emissions* are allocated into grids based on population (ORNL, 2006). \\
\hline Method 2 (M2) & $\begin{array}{l}\text { Provincial emissions* are allocated into grids based on Digital Chart of the World } \\
\text { (DCW) road network data. }\end{array}$ \\
\hline Method 3 (M3) & Provincial emissions* are allocated into grids based on the CDRM data. \\
\hline
\end{tabular}

* Provincial emissions are obtained through aggregating the county-level emissions calculated in this study.
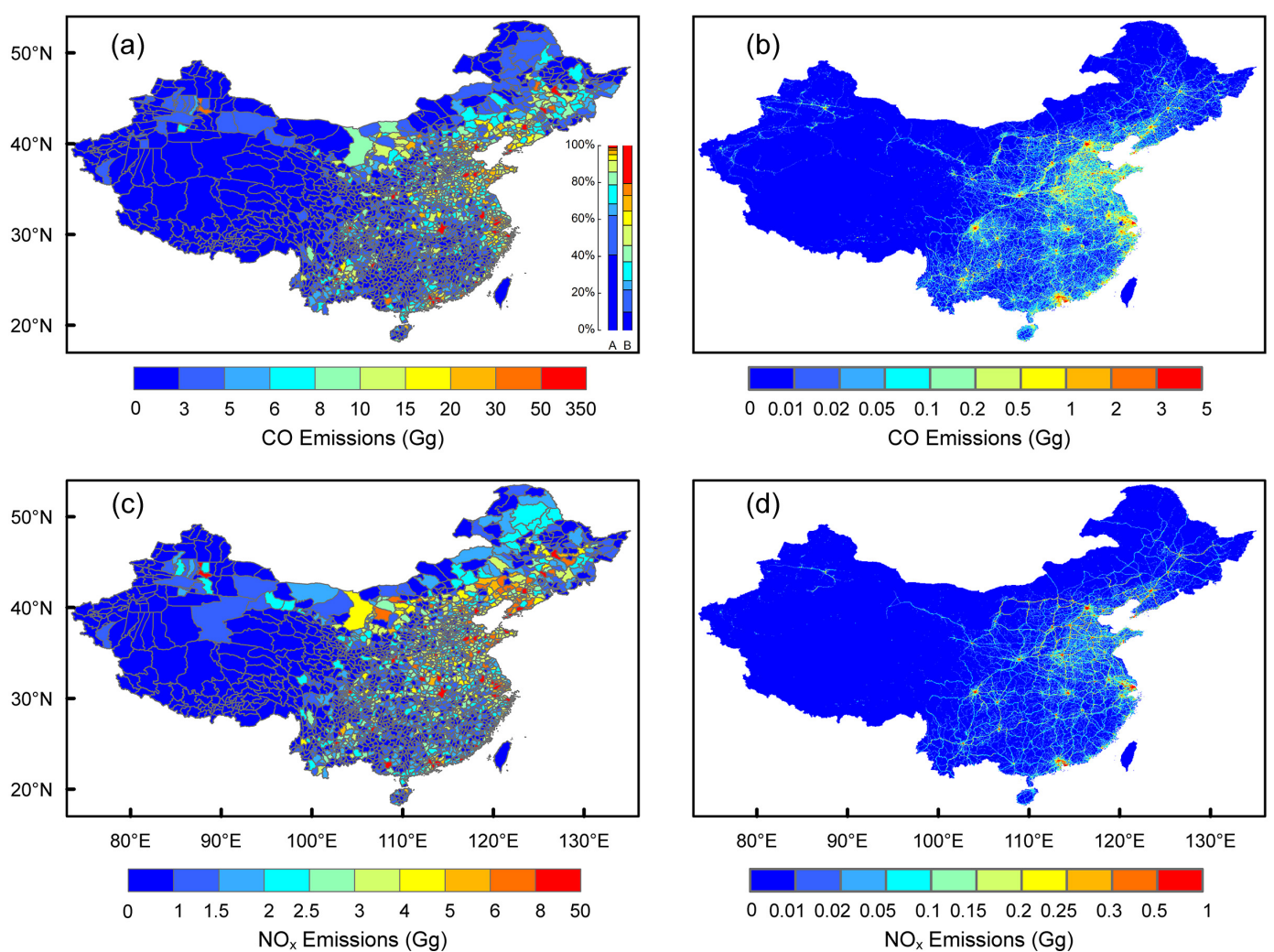

Figure 12. County and gridded emissions in 2008: (a) CO emissions by county (bar A represents the share of county numbers; bar B represents the share of county emissions); (b) gridded $\mathrm{CO}$ emissions at $0.05^{\circ} \times 0.05^{\circ}$ resolution; (c) $\mathrm{NO}_{\mathrm{x}}$ emissions by county and (d) gridded $\mathrm{NO}_{\mathrm{x}}$ emissions at $0.05^{\circ} \times 0.05^{\circ}$ resolution.

characteristics as line sources. M2 was not able to identify emission hotspots in big cities, because city roads are not included in DCW and few emissions could be allocated to urban areas. M3 could identify emission hotspots in cities but had less emissions allocated to major roads (e.g., intercounty highways) compared with our new method. The roadlength-based method assumed a proportional relationship between emissions and the road length regardless the road type. As a result, major roads that carry a higher traffic load than smaller roads were allocated less emissions than they should have been. The allocation method developed in this work was able to reflect the characteristics of vehicle emissions as line sources and could identify emission hotspots in cities, because of improvements in three aspects: (1) emissions are estimated at county level, (2) detailed road network data was used and (3) spatial distribution features of traffic activities were taken into consideration.

As the grid resolution became coarser, differences between the four methods became less significant because the spatial surrogates tended to have similar spatial distribution characteristics at a large spatial scale. As Fig. 14 shows, when the grid resolution was $0.5^{\circ}$, which is greater than most counties 

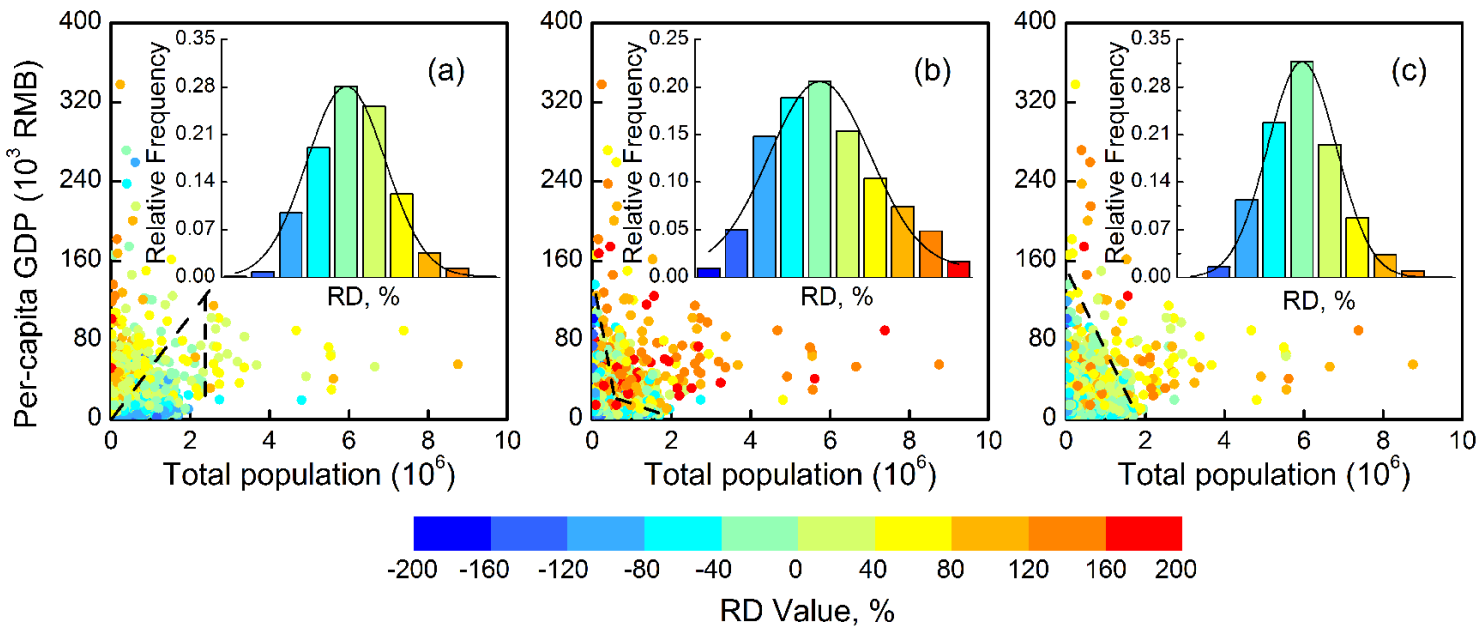

Figure 13. Distribution of the relative difference (RD) in gridded NMHC emissions at a resolution of $0.05^{\circ} \times 0.05^{\circ}$ between this work and other methods, and their relationships with county population and per-capita GDP: (a) this work versus M1; (b) this work versus M2 and (c) this work versus M3. RD is defined as $\mathrm{RD}_{i}=\left(\mathrm{E} 1_{i}-\mathrm{E} 22_{i}\right) /\left(\left(\mathrm{E} 1_{i}+\mathrm{E} 2_{i}\right) / 2\right)$, where $i$ represents county, $\mathrm{E} 1$ and $\mathrm{E} 2$ represent emissions by county generated from this study and other allocation methods (M1, M2, or M3). A positive (or negative) RD means that our method generates higher (or lower) emissions for this county than the other method.

in eastern China, the spatial distributions generated from the four methods had similar characteristics.

Figure 15 further explores the differences in gridded emissions between the methods at different resolutions. Gridded emissions became sensitive to spatial proxies when grid size is less than $0.2^{\circ}$, indicating that the accuracy of urban scaling modeling would be significantly impacted by spatial proxies used in bottom-up emissions. It is suggested that gridded emissions obtained from M1 is closer to this work than M2 for large urban areas at fine resolution (e.g., $0.05^{\circ}$, Fig. $15 \mathrm{~b}$ and $\mathrm{c}$ ). This is because using population as spatial proxy tends to allocate more emissions in urban area, while M2 was not able to identify emission hotspots in big cities as city roads are not included in DCW and few emissions could be allocated to urban areas. Using DCW as spatial proxy may introduce substantial underestimation of emissions in urban areas.

If the grid size was increased, the differences in the overall gridded emissions between the three methods were reduced. However, as Fig. 15d and e shows, both M1 and M2 methods may significantly underestimate the emissions of some grids with large populations (e.g., grids that cover Beijing, PRD and YRD), even though the grid size was enlarged to $1.0^{\circ}$ (equivalent to $100 \mathrm{~km} \times 100 \mathrm{~km}$ ). These highly populated regions are usually the key objective and focus of air quality modeling studies. Therefore, the allocation method developed in this study can provide better accuracy at both high and low resolution.

\subsection{VKT allocation weights}

We introduced the concept of VKT allocation weights to improve the accuracy of the gridded emission inventory. However, due to a lack of sufficient traffic survey data, the assumptions that we made for VKT weights may have created uncertainties in the gridded emission results. Therefore, we conducted a sensitivity analysis to quantify the sensitivity of the gridded emissions to the VKT allocation weights. Two scenarios (denoted as S1 and S2) were designed to represent the extreme values of VKT allocation weights for passenger vehicles and trucks, respectively, as shown in Table 5.

The results of the sensitivity analysis for $\mathrm{NMHC}$ and $\mathrm{NO}_{\mathrm{x}}$ emissions are presented in Fig. 16. As the $\mathrm{CO}$ result was similar to that of $\mathrm{NMHC}$, and the $\mathrm{PM}_{2.5}$ result to that of $\mathrm{NO}_{\mathrm{x}}$, this data is therefore not shown. As can be seen in Fig. 16a and $b$, on average, the difference in gridded emissions between this work and S1 ranged from -1 to $7 \%$, which suggests that the overall results were not very sensitive to the VKT weights of passenger vehicles. For each individual grid, the sensitivity of the emissions was dependent on the grid length ratio of county to inter-county roads ( $\mathrm{C}$ / I road ratio). If a grid had the same $\mathrm{C} / \mathrm{I}$ road ratio with the county where the grid was located, the emissions of this grid had zero sensitivity to the VKT weights of passenger vehicles. The greater the difference in the $\mathrm{C} / \mathrm{I}$ road ratios between a grid and its county, the more sensitive the gridded emissions were to the VKT weights. As shown in Fig. 16, compared with S1, this work allocated greater emissions to a few highly populated grids, because grids with a high population were more likely to have a higher $\mathrm{C} / \mathrm{I}$ road ratio than the county average. For a similar reason, this work allocated lower emissions than 
Table 5. Sensitivity analysis scenarios of vehicle kilometers traveled (VKT) allocation weights.

\begin{tabular}{|c|c|}
\hline Scenarios & Description \\
\hline $\begin{array}{l}\text { Base scenario } \\
\text { (This work) }\end{array}$ & $\begin{array}{l}\text { The VKT distribution weights for passenger vehicles and trucks are shown } \\
\text { in Table } 1 .\end{array}$ \\
\hline Scenario 1 (S1) & $\begin{array}{l}\text { Same as the Base scenario, except that } 50 \% \text { VKT of passenger vehicles are } \\
\text { allocated to county roads and } 50 \% \text { VKT to inter-county roads, which assumes the } \\
\text { same VKT for county and inter-county roads. Because passenger vehicles travel } \\
\text { more often in urban areas, S1 represents an extreme case for passenger vehicles. }\end{array}$ \\
\hline Scenario 2 (S2) & $\begin{array}{l}\text { Same as the Base scenario, except that the VKT weights of trucks on county roads } \\
\text { and inter-county roads are } 63 \% \text { and } 37 \% \text {, respectively, the same as the length } \\
\text { ratios of these two types of road in China*. Because trucks are driven more } \\
\text { intensively on inter-county roads than on county roads, assuming the same VKT } \\
\text { per unit of road length for county and inter-county roads can be regarded as an extreme } \\
\text { case for trucks. }\end{array}$ \\
\hline
\end{tabular}

* In China, county roads made up $63 \%$ and inter-county roads $37 \%$ of the total road length, according to the CDRM.

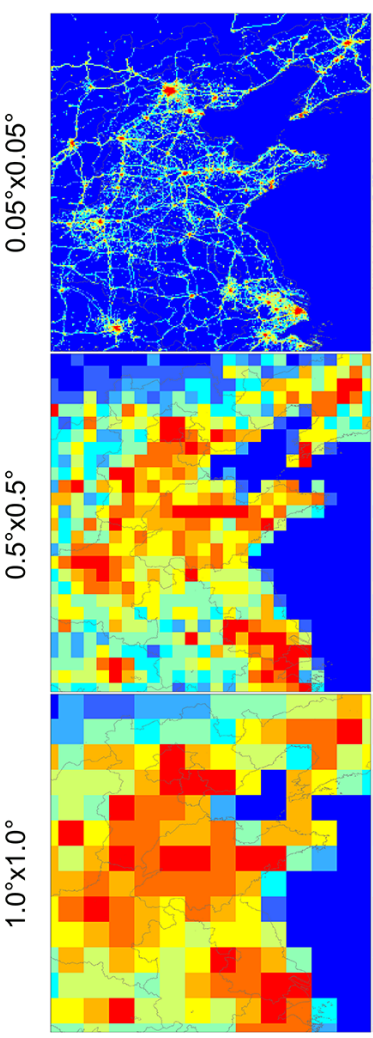

(a)

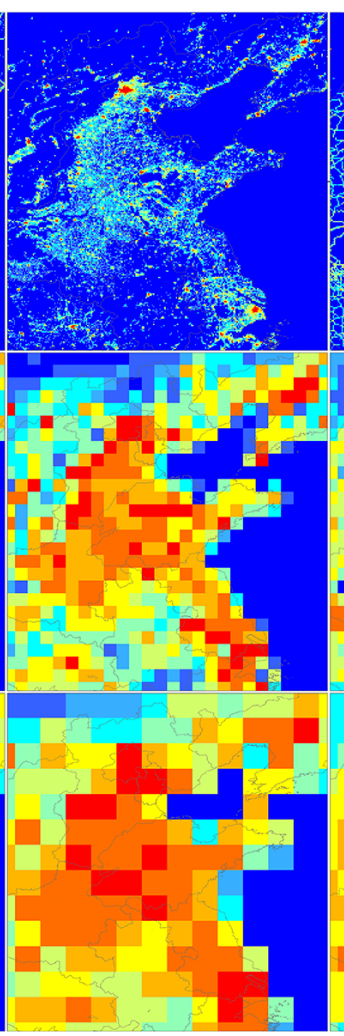

(b)

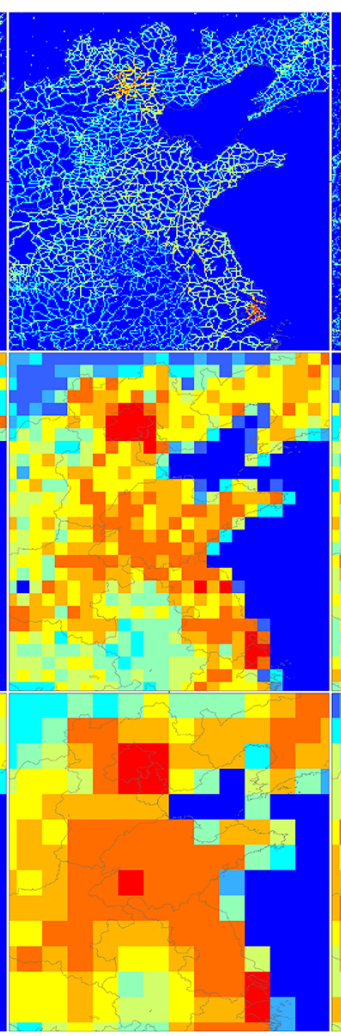

(c)

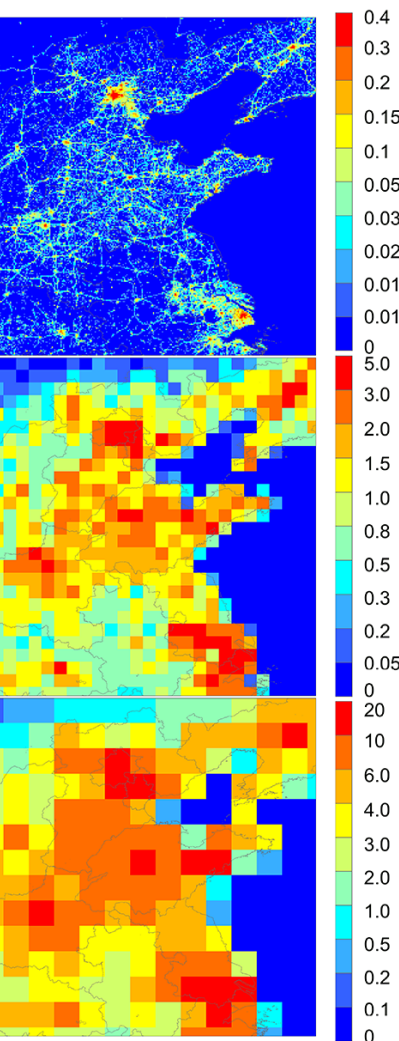

(d)

Figure 14. Vehicle NMHC emissions from different spatial allocation methods: (a) this work; (b) population-based method (M1); (c) DCWbased method (M2) and (d) CDRM-based method (M3).

S1 for some grids with low populations. If a grid had $100 \%$ county roads and no inter-county roads, and its county had a $\mathrm{C} / \mathrm{I}$ road ratio of 1.7 (the national average in China), which is an extreme and rare case, the change of the VKT weights for county roads from 80 to $50 \%$ could cause a maximal reduction of $60 \%$ in the gridded emissions of passenger vehi- cles. Under a normal scenario, the emission change would have been much smaller.

As Fig. 16c and d shows, the sensitivity of emissions to the VKT weights of trucks was small, given that the average difference in the gridded $\mathrm{NMHC}$ and $\mathrm{NO}_{\mathrm{x}}$ emissions between this work and $\mathrm{S} 2$ ranged from -2 to $2 \%$. Furthermore, 

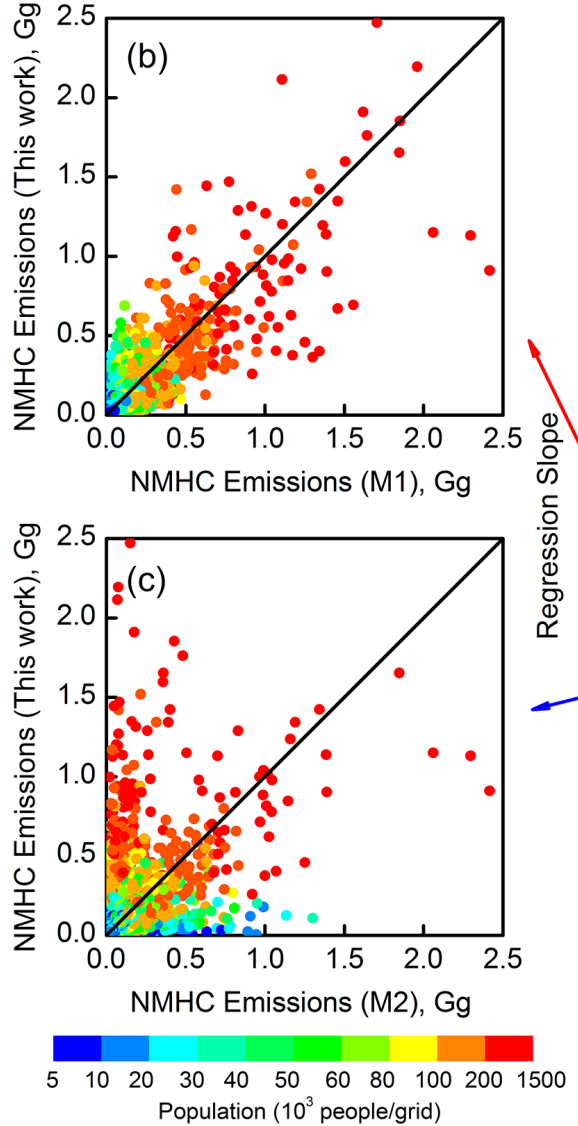
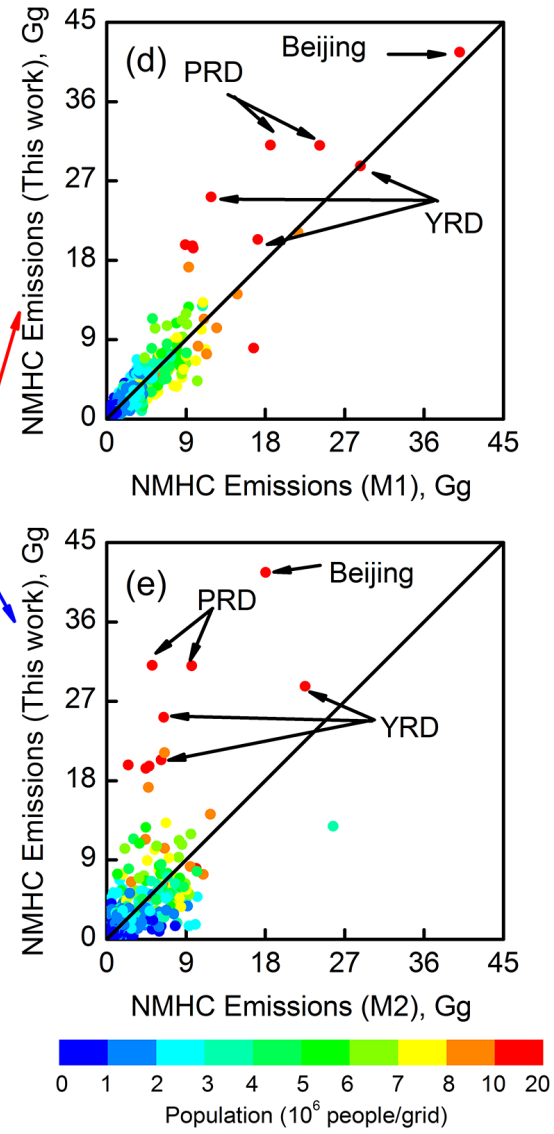

Figure 15. Comparison of the gridded emissions with different allocation methods: (a) average differences of gridded emissions between M1, M2 and this work at various resolutions; (b) this work versus M1 at a resolution of $0.05^{\circ} \times 0.05^{\circ}$; (c) this work versus M2 at a resolution of $0.05^{\circ} \times 0.05^{\circ} ;(\mathbf{d})$ this work versus M1 at a resolution of $1.0^{\circ} \times 1.0^{\circ}$ and (e) this work versus M2 at a resolution of $1.0^{\circ} \times 1.0^{\circ}$.

for individual grids, the sensitivity of emissions to the VKT weight of trucks was related to the grid C / I road ratio, as was the case with the VKT weights of passenger vehicles. Increasing the VKT weights of trucks from 8-25\% (this work) to $63 \%$ (S2) allocated more truck emissions to highly populated grids because these grids tended to have higher C / I road ratios, and vice versa for grids with low populations. However, as shown by Fig. 16c, the NMHC emissions of highly populated grids were observed to have little sensitivity to VKT weights of trucks, because passenger vehicles usually dominated the NMHC emissions in highly populated grids and trucks played only a very limited role.

\section{Discussion}

This work proposes a new inventory methodology to improve the spatial and temporal accuracy and resolution of vehicle emissions for China. By developing a set of approaches to estimate, for the first time, the vehicle emissions for each county, and introducing the VKT allocation weights to assign county emissions into grids, our proposed methodology overcomes the common weakness of previous methods, such as, neglecting the geographical differences in crucial parameters of vehicle emissions and using surrogates that are weakly related to vehicle activities to allocate vehicle emissions.

Compared with previous methods, the new methodology has great advantages in portraying the spatial distribution characteristics of vehicle activities and emissions. However, uncertainties still exist in two aspects - vehicle emission factors and vehicle activities. In this work, vehicle emission factors were simulated by a US IVE model that was adjusted with hundreds of on-road vehicle emission measurements in China. The uncertainty in these emission factors lies in the representativeness of the selected measured vehicles. To lower this uncertainty, more measurements are required and eventually a vehicle emission model needs to be developed for China. This work did not include the spatial variations in emission factors induced by driving conditions due to the limitation of data availability. The national average driving patterns are used in this work, which are calculated on the basis of measurements in about 20 cities in China (Wang et al., 2008). A sensitivity analysis on CO emission factors of LDBs for Beijing and Changchun (one megacity with 

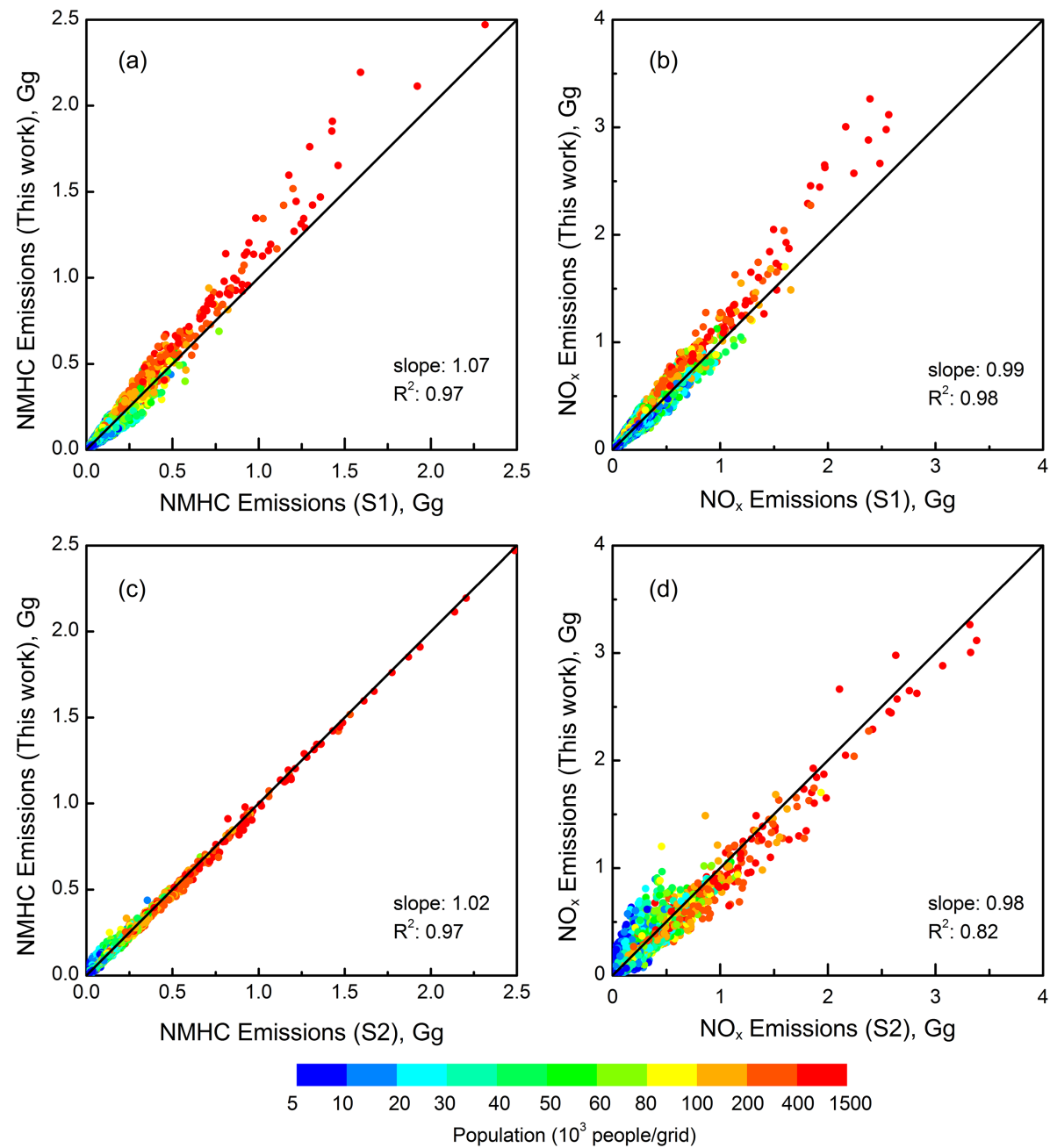

Figure 16. Comparison of gridded emissions at a resolution of $0.05^{\circ} \times 0.05^{\circ}$ between this work and the two sensitivity cases ( $\mathrm{S} 1$ and $\mathrm{S} 2$ ): (a) gridded $\mathrm{NMHC}$ emissions of this work versus $\mathrm{S} 1$; (b) gridded $\mathrm{NO}_{\mathrm{x}}$ emissions of this work versus $\mathrm{S} 1$; (c) gridded $\mathrm{NMHC}$ emissions of this work versus $\mathrm{S} 2$ and (d) gridded $\mathrm{NO}_{\mathrm{x}}$ emissions of this work versus $\mathrm{S} 2$.

frequent traffic congestions and one midsize city with less traffic congestions) found that using locally driven cycles will lead to $6 \%$ increase of $\mathrm{CO}$ emission factor in Beijing and $18 \%$ decrease in Changchun comparing with national average driving cycles. On the other hand, the vehicle activities are determined based on surveys conducted in a few cities and on several assumptions, which could involve uncertainties because of the disparity in vehicle activities between cities. To improve the data quality, dynamic traffic flow should be integrated into the inventory, which will require collaboration with traffic management research groups.
Addressing these uncertainties requires long-term efforts from the research community and concrete support from various governmental sectors for data availability and sharing. In the meantime, we will continue to improve the methodology by addressing the remaining key issues, including VKT by county, different technology distributions within the same province, base emission factors by road type, and more reliable VKT weights. We also plan to extend this methodology from 2008 onwards to perform a multi-year analysis.

The Supplement related to this article is available online at doi:10.5194/acp-14-9787-2014-supplement. 
Acknowledgements. This work is funded by China's National Basic Research Program (2010CB951803, 2014CB441301), the National Science Foundation of China (41005062, 41175124, 41222036, and 71322304) and the Tsinghua University Initiative Research Program (2011Z01026). We thank James Lents for providing the IVE model. We also thank two anonymous reviewers for their constructive comments to this paper. Q. Zhang and K. B. He acknowledge support from the Collaborative Innovation Centre for Regional Environmental Quality.

Edited by: H. Su

\section{References}

Bishop, G. A., Morris, J. A., Stedman, D. H., Cohen, L. H., Countess, R. J., Countess, S. J., Maly, P., and Scherer, S.: The Effects of Altitude on Heavy-Duty Diesel Truck On-Road Emissions, Environ. Sci. Technol., 35, 1574-1578, doi:10.1021/es001533a, 2001.

Cai, H. and Xie, S. D.: Estimation of vehicular emission inventories in China from 1980 to 2005, Atmos. Environ., 41, 8963-8979, doi:10.1016/j.atmosenv.2007.08.019, 2007.

Dargay, J. and Gately, D.: Income's effect on car and vehicle ownership, worldwide: 1960-2015, Transport. Res. A-Pol., 33, 101138, doi:10.1016/s0965-8564(98)00026-3, 1999.

Dargay, J., Gately, D., and Sommer, M.: Vehicle ownership and income growth, worldwide: 1960-2030, Energy J., 28, 143-170, 2007.

Davis, N., Lents, J., Osses, M., Nikkila, N., and Barth, M.: Part 3: Developing Countries: Development and Application of an International Vehicle Emissions Model, Transp. Res. Record, 1939, 155-165, doi:10.3141/1939-18, 2005.

Huo, H. and Wang, M.: Modeling future vehicle sales and stock in China, Energ. Policy., 43, 17-29, doi:10.1016/j.enpol.2011.09.063, 2012.

Huo, H., Zhang, Q., He, K., Wang, Q., Yao, Z., and Streets, D. G.: High-Resolution Vehicular Emission Inventory Using a LinkBased Method: A Case Study of Light-Duty Vehicles in Beijing, Environ. Sci. Technol., 43, 2394-2399, doi:10.1021/es802757a, 2009.

Huo, H., Zhang, Q., He, K., Yao, Z., Wang, X., Zheng, B., Streets, D. G., Wang, Q., and Ding, Y.: Modeling vehicle emissions in different types of Chinese cities: Importance of vehicle fleet and local features, Environ. Pollut., 159, 2954-2960, doi:10.1016/j.envpol.2011.04.025, 2011.

Huo, H., Yao, Z., Zhang, Y., Shen, X., Zhang, Q., Ding, Y., and He, K.: On-board measurements of emissions from light-duty gasoline vehicles in three mega-cities of China, Atmos. Environ., 49, 371-377, doi:10.1016/j.atmosenv.2011.11.005, 2012a.

Huo, H., Yao, Z., Zhang, Y., Shen, X., Zhang, Q., and He, K.: On-board measurements of emissions from diesel trucks in five cities in China, Atmos. Environ., 54, 159-167, doi:10.1016/j.atmosenv.2012.01.068, 2012b.

Huo, H., Zhang, Q., He, K., Yao, Z., and Wang, M.: Vehicle-use intensity in China: Current status and future trend, Energ. Policy, 43, 6-16, doi:10.1016/j.enpol.2011.09.019, 2012c.

Liu, H., He, K. B., Wang, Q. D., Huo, H., Lents, J., Davis, N., Nikkila, N., Chen, C. H., Osses, M., and He, C. Y.: Comparison of vehicle activity between Beijing and Shanghai, J.
Air Waste Manage. Assoc., 57, 1172-1177, doi:10.3155/10473289.57.10.1172, 2007.

Liu, H., He, K., Lents, J. M., Wang, Q., and Tolvett, S.: Characteristics of Diesel Truck Emission in China Based on Portable Emissions Measurement Systems, Environ. Sci. Technol., 43, 95079511, doi:10.1021/es902044x, 2009.

Nam, E., Fulper, C., Warila, J., Somers, J., Michaels, H., Baldauf, R., Rykowski, R., and Scarbro, C.: Analysis of Particulate Matter Emissions from Light-Duty Gasoline Vehicles in Kansas City, US Environmental Protection Agency, http://www. epa.gov/otaq/emission-factors-research/420r08010.pdf (last access: 29 November 2013), 2008.

National Bureau of Statistics: China Statistical Yearbook for Regional Economy 2002-2011, China Statistics Press, Beijing, 2002-2011.

National Bureau of Statistics: China Statistical Yearbook 19952009, China Statistics Press, Beijing, 1995-2009.

National Bureau of Statistics: China Statistical Yearbook 20032009, China Statistics Press, Beijing, 2003-2009.

National Bureau of Statistics: China Statistical Yearbook for Regional Economy 2009, China Statistics Press, Beijing, 2009a.

National Bureau of Statistics: China Statistical Yearbook 2009, China Statistics Press, Beijing, 2009b.

Niemeier, D., Zheng, Y., and Kear, T.: UCDrive: a new gridded mobile source emission inventory model. Atmos. Environ., 38, 305319, doi:10.1016/j.atmosenv.2003.09.040, 2004.

Ohara, T., Akimoto, H., Kurokawa, J., Horii, N., Yamaji, K., Yan, X., and Hayasaka, T.: An Asian emission inventory of anthropogenic emission sources for the period 1980-2020, Atmos. Chem. Phys., 7, 4419-4444, doi:10.5194/acp-7-4419-2007, 2007.

Oak Ridge National Laboratory (ORNL): LandScan Global Population Database, Oak Ridge National Laboratory, Oak Ridge, Tenn., USA, 2006.

Ossés de Eicker, M., Zah, R., Triviño, R., and Hurni, H.: Spatial accuracy of a simplified disaggregation method for traffic emissions applied in seven mid-sized Chilean cities, Atmos. Environ., 42, 1491-1502, doi:10.1016/j.atmosenv.2007.10.079, 2008.

Saide, P., Zah, R., Osses, M., and Ossés de Eicker, M.: Spatial disaggregation of traffic emission inventories in large cities using simplified top-down methods, Atmos. Environ., 43, 4914-4923, doi:10.1016/j.atmosenv.2009.07.013, 2009.

Schneider, A., Friedl, M. A., and Potere, D.: A new map of global urban extent from MODIS satellite data, Environ. Res. Lett., 4, 044003, doi:10.1088/1748-9326/4/4/044003, 2009.

Streets, D. G., Bond, T. C., Carmichael, G. R., Fernandes, S. D., Fu, Q., He, D., Klimont, Z., Nelson, S. M., Tsai, N. Y., Wang, M. Q., Woo, J. H., and Yarber, K. F.: An inventory of gaseous and primary aerosol emissions in Asia in the year 2000, J. Geophys. Res.-Atmos., 108, 8809, doi:10.1029/2002JD003093, 2003.

Tuia, D., Ossés de Eicker, M., Zah, R., Osses, M., Zarate, E., and Clappier, A.: Evaluation of a simplified topdown model for the spatial assessment of hot traffic emissions in mid-sized cities, Atmos. Environ., 41, 3658-3671, doi:10.1016/j.atmosenv.2006.12.045, 2007.

Wang, H. K., Fu, L. X., Lin, X., Zhou, Y., and Chen, J. C.: A bottom-up methodology to estimate vehicle emissions for the Beijing urban area, Sci. Total. Environ., 407, 1947-1953, doi:10.1016/j.scitotenv.2008.11.008, 2009. 
Wang, M., Huo, H., Johnson, L., and He, D.: Projection of Chinese Motor Vehicle Growth, Oil Demand, and $\mathrm{CO}_{2}$ Emissions through 2050, Argonne National Laboratory, http://www. osti.gov/scitech/biblio/898531 (last access: 29 November 2013), 2006.

Wang, Q. D., He, K. B., Huo, H., and Lents, J.: Real-world vehicle emission factors in Chinese metropolis city - Beijing, J. Environ. Sci.-China, 17, 319-326, 2005.

Wang, Q. D., Huo, H., He, K., Yao, Z. L., and Zhang, Q.: Characterization of vehicle driving patterns and development of driving cycles in Chinese cities, Transport. Res. Part D-Tr. E., 13, 289297, doi:10.1016/j.trd.2008.03.003, 2008.

Weilenmann, M., Favez, J.-Y., and Alvarez, R.: Cold-start emissions of modern passenger cars at different low ambient temperatures and their evolution over vehicle legislation categories, Atmos. Environ., 43, 2419-2429, doi:10.1016/j.atmosenv.2009.02.005, 2009.

Wei, W., Wang, S., Chatani, S., Klimont, Z., Cofala, J., and Hao, J.: Emission and speciation of non-methane volatile organic compounds from anthropogenic sources in China, Atmos. Environ., 42, 4976-4988, doi:10.1016/j.atmosenv.2008.02.044, 2008.
Yao, Z., Wang, Q., He, K., Huo, H., Ma, Y., and Zhang, Q.: Characteristics of real-world vehicular emissions in Chinese cities, J. Air Waste Manage. Assoc., 57, 1379-1386, doi:10.3155/10473289.57.11.1379, 2007.

Yao, Z., Huo, H., Zhang, Q., Streets, D. G., and He, K.: Gaseous and particulate emissions from rural vehicles in China, Atmos. Environ., 45, 3055-3061, doi:10.1016/j.atmosenv.2011.03.012, 2011

Zhang, Q., Streets, D. G., Carmichael, G. R., He, K. B., Huo, H., Kannari, A., Klimont, Z., Park, I. S., Reddy, S., Fu, J. S., Chen, D., Duan, L., Lei, Y., Wang, L. T., and Yao, Z. L.: Asian emissions in 2006 for the NASA INTEX-B mission, Atmos. Chem. Phys., 9, 5131-5153, doi:10.5194/acp-9-5131-2009, 2009.

Zheng, J., Che, W., Wang, X., Louie, P., and Zhong, L.: RoadNetwork-Based Spatial Allocation of On-Road Mobile Source Emissions in the Pearl River Delta Region, China, and Comparisons with Population-Based Approach, J. Air Waste Manage. Assoc., 59, 1405-1416, doi:10.3155/1047-3289.59.12.1405, 2009. 